\title{
LA II REPÚBLICA Y EL ESTATUTO ORGÁNICO DE LOS TERRITORIOS ESPAÑOLES DEL GOLFO DE GUINEA, 1931-1936
}

\section{THE SPANISH SECOND REPUBLIC AND THE ORGANIC STATUTE OF THE SPANISH TERRITORIES OF THE GULF OF GUINEA, 1931-1936}

\author{
José Luis Bibang Ondo Eyang \\ Universidad de Huelva
}

\begin{abstract}
SUMARIO: I. CONSIDERAIONES PREVIAS.- II. EL PREÁMBULO DEL ESTATUTO COLONIAL: DE LA RENTABILIZACIÓN A LA REPUBLICACÓN DE LOS TERRITORIOS ESPAÑOLES DEL GOLFO DE GUINEA.- III. LA ADMINISTRACIÓN DE LOS TERRITORIOS ESPAÑOLES: ÓRGANOS Y ORGANIZACIÓN TERRITORIAL.- IV. COMPETENCIAS LEGISLATIVAS DEL GOBERNADOR. V. COMPETENCIAS SACIONADORAS DEL GOBERNADOR.- VI. COMTENCIAS SANCIONADORAS DEL GOBERNADOR.- VI.COMPETENCIAS DIPLOMÁTICAS DEL GOBERNADOR.- VII. COMPETENCIAS DIRECTIVAS.- VIII. CONSIDERACIONES FINALES.
\end{abstract}

Resumen: "Nos encontramos delante de una constitución", observó Sánchez Albornoz, "que procura mantener el equilibrio entre la realidad y el ideal, entre el pasado y el mañana, esas dos fuerzas eternamente en choque a través del tiempo y del espacio". La regulación del hecho colonial no pudo reflejar mejor las sabias palabras del diputado de Acción Republicana. El colonialismo era la afirmación de la desigualdad entre los pueblos, la negación de su libertad. Pero, desgraciadamente, a las alturas de 1931 parecía impensable su renuncia, no sólo por parte de la joven República española, sino también por el resto de los Estados coloniales. Las siguientes lineas hacen un breve repaso del reflejo en las normas republicanas de aquel choque entre los ideales de la República y los principios del colonialismo, "un pasado" y "una realidad" asunta por la joven democracia española. Nuestra norma de referencia ha sido el decreto de 22 de julio de 1931, por el que se aprobó el nuevo estatuto orgánico para los Territorios Españoles del Golfo de Guinea.

\begin{abstract}
In August 1931, during the presentation of the project of the Spanish republican constitution, Sánchez Albornoz said: "[...] we are before a constitution that seeks to maintain a balance between reality and deal, between the past and the future, those two forces eternally in collision through the time and the space". The colonial legal reforms approved by the Spanish Second Republic were a good reflection of those Albonoz's words. The colonialism was the affirmation of inequality between people, it was the denial of the freedom of peoples. But, unfortunately, by 1931, its resignation was unthinkable, not only by the Spanish Republic, but also by the rest of the colonial states. The aim of this review, is to surline how that clash between republican ideals and those of colonialism, "a past" and "a reality" assumed by the young spanish democracy, was reflected in the colonial reforms approved by the new Spanish government. This work is focus on the decree of 22 of July 1931, which approved the new Organic Statute for Spanish Guinea.
\end{abstract}


Palabras clave: II República, Territorios Españoles del Golfo de Guinea, Estatuto Orgánico, Gobernador General.

Key words: Second Republic, Spanish Territories of The Gulf of Guinea, Organic Statute, General Governor.

\section{CONSIDERACIONES PREVIAS.}

El vocabulario, según Fradera ${ }^{1}$, constituyó uno de los primeros puntos de ruptura entre el Constituyente gaditano y el colonialismo pre-liberal. En las Constituyentes gaditanas, términos como imperio, colonias, dominios, o posesiones, fueron sustituidos por términos o giros como territorios de ambos hemisferios, territorios de ultramar, provincias de ultramar, o simplemente ultramar. Cristina N. Da Silva ${ }^{2}$, resaltando la impronta del gaditano en el constituyente portugués de 1822, recuerda que el término ultramar no hacía referencia a los territorios controlados por Portugal en África. Sin embargo, tanto el constitucionalismo gaditano como el Ventista, siguieron utilizando la terminología del colonialismo clásico para referirse a África. Sus territorios en dicho continente eran propiedades, posesiones, dominios, plazas, departamentos, colonias, o simplemente territorios en el mejor de los casos. Efectivamente, la Guinea Española, hasta su total asimilación jurídica en 1959², fue siempre considerada una posesión, una colonia ${ }^{4}$. Y, como tal, administrada al margen de

1 Josep $\mathrm{M}^{\mathrm{a}}$ Fradera, Colonias para después de un Imperio, Editorial Bellaterra, Barcelona, 2005, p. 62

2 Cristina Nogueira Da Silva, Constitucionalismo e imperio, A ciudadania no Ultramar português, Edições Almeida, Coimbra, 2009, p. 384

3 Fue una ley de julio de 1959 la que incorporó Guinea como una provincia de España. Desde entonces los guineanos adquirieron la ciudadanía española y pudieron designar procuradores en las Cortes españolas. Antes de 1959, los nativos de Guinea ni eran extranjeros, ni eran ciudadanos españoles. Eran, simplemente, súbditos de la monarquía española, o si se prefiere el eufemismo, eran españoles, pero “de segunda". Sobre los cambios que supuso esta provincialización de la Guinea Española, puede leerse, a título ilustrativo: Antonio Manuel Carrasco González, "Estatuto del Indigena en la Guinea Española: nacionalidad, ciudadanía y capacidad”, e-Legal History Journal, no 12, 2011, p. 18; Adolfo Obiang Bikó, Guinea Ecuatorial: del colonialismo español al descubrimiento del petróleo, Sial Ediciones, Madrid, 2016, pp. 99-133; Donato Ndongo Bidyogo, Historia y tragedia de Guinea Ecuatorial, Editorial Cambio 16, Madrid, 1977, pp. 79-95; Fernando Ballano Gonzalo, Aquél negrito del África tropical: el colonialismo español en Guinea (1778-1968), Sial Ediciones, Madrid, 2014, pp. 528 y ss; Mariano De Castro y Donato Ndongo, España en Guinea Ecuatorial: construcción del desencuentro, Sequitur, Madrid, 1998, pp. 192 y ss; Olegario Negrín Fajardo, Historia de la educación en Guinea Ecuatorial. El modelo educativo colonial español, UNED, Madrid, 1993, pp. 142 y ss.; Ley 46/1959, de 30 de julio sobre organización y régimen jurídico de las Provincias Africanas $\left(\mathrm{BOE} \mathrm{N}^{\circ} 182\right.$, de 31/07/1959, pp. 10370-10379 disponible https://www.boe.es/datos/datos/pdfs/BOE//1959/182/A10370-10371.pdf )

4 El primer estatuto colonial de Guinea empezaba precisamente con un fragmento que condensaba casi toda esta terminología utilizada por el colonialismo clásico para referirse a los territorios africanos: "Desde que en 1778 adquirió España sobre la costa occidental de África sus posesiones actuales de Fernando Poo y Annobón, aumentadas en 1843 con la isla de Corisco y sus dependencias de Elobey, y muy recientemente con el territorio de Cabo San Juan, se han intentado varias expediciones a fin de establecer de una manera efectiva la propiedad nacional sobre aquellos dominios; pero todas las tentativas han fracasado por diversos accidentes que han reconocido una causa común”. Véase Agustín Miranda Junco, Leyes Coloniales: Legislación de los territorios españoles del Golfo de Guinea, Imprenta Sucesores de Rivadeneyra, Madrid, 1945, p. 23 
los regímenes constitucionales que se sucedieron en la metrópoli, sujeta a sus propios estatutos orgánicos ${ }^{5}$. La República, tan pronto como pudo, preparó un nuevo estatuto para la colonia, aprobado por decreto de 22 de julio del 31; es la norma a la que, para facilitar su reiterada cita en este trabajo, me referiré siempre como Estatuto Colonial Republicano, abreviado en adelante como ECR.

La brevedad del decreto no fue precisamente una peculiaridad del legislador de 1931. Si exceptuamos las cartas coloniales de 1858, 1868 y 1904, todas con treinta y seis preceptos, los otros estatutos pre-republicanos también fueron bastante concisos: el de 1872 se resumió en diez y seis artículos, el de 1880 , en catorce, y el de 1888, en tan sólo doce. Pero aun careciendo de este carácter innovador, el laconismo del ECR no estuvo privado de toda justificación lógica. Por una parte, en tanto que mini-constitución colonial, sus catorce bases (o artículos) del ECR, más que agotar la regulación de las materias ahí abordadas, debieron ser pensadas tanto para establecer las competencias de los principales órganos coloniales, como para condensar aquellos principios rectores en que luego debía inspirarse la sucesiva normativa aprobada en desarrollo y ejecución de la política colonial. Por otra parte, el laconismo del ECR era también justificable desde su contexto político circundante. Siendo el decreto obra del gobierno provisional, su contenido mínimo era perfectamente concebible dentro de la lógica de transitoriedad de una legislación pre-constitucional cuyo objetivo, como bien se dedujo del discurso de Alcalá Zamora ${ }^{6}$, no era otro que adoptar medidas puntuales y provisionales para paliar demandas sociales que luego serian profundamente abordadas tanto por la Asamblea Constituyente como por las Cortes y demás poderes emanados del futuro y nuevo régimen constitucional.

El tránsito de la legislación provisional a la post-constitucionalidad desveló que los republicanos también partieron de la concepción del Estado colonial como un territorio en el que se yuxtaponian dos espacios jurídicamente distintos: el metropolitano y el colonial. En el primero, el republicanismo se tradujo en un centralismo parlamentario cuya base y lógica lockeanas, para la afirmación de la constitucionalidad de las disposiciones pre-constitucionales, imponian el necesario consenso del pueblo, único soberano, creador y signatario del contrato social. Los decretos del gobierno provisional pasaron por el referido filtro democrático. Sus mandatos, además de ser constitucionalizados según los principios de la Carta, fueron desarrollados en leyes aprobadas por las Cortes durante el primer bienio llamado reformista.

5 En el lapso que va de 1778 a 1945, periodo que comprende la compilación legislativa de Miranda Junco, se sucedieron en la Guinea colonial un total de diez estatutos. Seis de los cuales precedieron al régimen republicano: el de 1858 (real decreto de 13 de diciembre de 1858), el de 1868 (decreto de 12 de noviembre de 1868), el de 1872 (real decreto de 26 de octubre de 1872), el de 1880 (real decreto de 26 de noviembre de 1880), el de 1888 (real decreto. de 17 de febrero de 1888), y el de 1904 (real decreto de 11 de julio de 1904). Durante la República, se sucedieron dos estatutos orgánicos: uno de 1931 (decreto de 22 de julio de 1931) y otro de 1935 (decreto de 11 de noviembre de 1935). Este último, no sólo reprodujo el texto precedente, sino que tampoco le añadió gran novedad. Caída la República, el Franquismo aprobó su primer estatuto orgánico colonial el 27 de agosto de 1938. Véase Agustín Miranda Junco, Leyes coloniales..., op. cit., pp. 23-26, 57-59, 63-66, 70-71, 82-84, 138-142, 806-808, 1139-1142

${ }^{6}$ Niceto Alcalá Zamora, "Discurso de declaración de la República de 14 de abril de 1931", Cuadernos Republicanos, $\mathrm{n}^{\circ}$ 42, 2000, pp. 7-8. 
Pero si el parlamentarismo fue el rostro del republicanismo en la metrópoli, el centralismo del ejecutivo siguió siéndolo, sin embargo, en los Territorios Españoles del Golfo de Guinea (en delante TTEEGG). La concepción de los mismos como un espacio de precaria seguridad hizo que el principio democrático terminara cediendo al imperativo del orden público. Si se estimaba que la inmediatez debía regir la acción del gobernador en garantía de la seguridad, o si, según se decía, sus poderes debían gozar de amplia libertad en el cumplimiento de ese cometido ${ }^{7}$, entonces resultaba lógico eludir los lentos procedimientos parlamentarios no sólo en el control de proporcionalidad de las medidas de la autoridad colonial ante circunstancias de grave alteración del orden colonial, sino también en el control de constitucionalidad tanto de los principios rectores del estatuto colonial como del resto de disposiciones coloniales.

Ciertamente, ni la sujeción de la norma colonial al principio de legalidad -en sentido estricto debe confundirse con la asimilación jurídica de las colonias, ni la constitucionalización del régimen colonial debe confundirse con su democratización. Que las Constituyentes republicanas omitieran un serio debate sobre el régimen de Guinea y demás colonias, y que la Carta resultante se limitara a declarar la competencia exclusiva del ejecutivo sobre las colonias (art. $14.3^{a}$ de la Constitución del 31$)^{8}$, sólo deben ser considerados indicios, pero nunca evidencias definitivas, que corroboran la negación de los valores republicanos al espacio colonial. Como se sabe, el "apartheid constitucional" de Guinea trascendia una dimensión meramente formal ${ }^{9}$. Además del carácter especial y excepcional de la norma que la regia, entre sus disposiciones y sus destinatarios se interponía el poder fáctico del gobernador $y$ una praxis administrativa cuya arbitrariedad hacía incluso pasar por justas las tibias garantías legales a favor de los súbditos coloniales. Consecuentemente, cualquier proyecto de republicanización o, lo que es lo mismo, cualquier propósito de democratización del ordenamiento colonial, más que centrarse en los principios de la Carta magna estableciendo la competencia del parlamento sobre las colonias, debia implicar un serio compromiso para superar el carácter segregacionista de la ley colonial y terminar con la ejecución arbitraria que hacian de la misma tanto el gobernador como el resto de agentes en su trato hacia los colonizados.

En este ensayo se pretende determinar si la verdadera intención de los republicanos fue liberalizar el régimen colonial, como se recogía en la exposición

7 “[...] creo que las autoridades de Fernando Póo, por la situación especial en que se encuentra aquel territorio, deben disponer de una gran amplitud de medios, que no se pueden someter al régimen de la Península. Entiendo, sin ahondar más en el problema, que una definición de tal género en la Constitución no es necesaria y que, como casi todas las cosas innecesarias en ella, vendría a resultar perjudicial y perturbadora en la práctica". Véase la intervención de Santiago Alba Bonifaz en el Diario de sesiones de las cortes, sesión de las Cortes Constituyentes de $01 / 12 / 1931$

8 Art.14 de la Constitución española de 1931: "Son de la exclusiva competencia del Estado español la legislación y la ejecución directa en las materias siguientes: [1 ${ }^{\mathrm{a}}, 2^{\mathrm{a}}$,] $3^{\mathrm{a}}$. Representación diplomática y consular y, en general, la del Estado en el exterior; declaración de guerra; Tratados de paz; régimen de Colonias y Protectorado, y toda clase de relaciones internacionales".

9 Expresión utilizada por Bartolomé Clavero para referirse a la situación de exclusión constitucional que caracterizó los TTEEGG a lo largo del constitucionalismo liberal español. Véase Bartolomé Clavero, "Bioko, 1837-1876: Constitucionalismo de Europa en África, derecho internacional consuetudinario del trabajo mediante”, Quaderni Fiorentini, vol. 35, 2006, p. 454 
de motivos del ECR ${ }^{10}$. Si la reforma del estatuto de 1904 obedecía a "directrices" más congruentes con el nuevo credo político, si el progresismo republicano repercutía en el espacio colonial, entonces era lógico que los coloniales (me refiero a los residentes en Guinea) creyeran que la República reglaría la activación de "la cláusula de protección del orden público colonial" 11 , fundamento del absolutismo de los gobernadores; que el nuevo régimen garantizaría sus derechos, regulándolos e interpretándolos en un sentido amplio y coherente con los valores democrático-republicanos. En los siguientes epígrafes se sitúa la Carta colonial republicana en sus cinco años de vigencia en Guinea, analizando no solamente hasta qué punto el tenor de sus disposiciones supuso un discurso mesiánico convincente en la colonia, sino sobre todo hasta qué punto la interpretación y la praxis de tales mandatos estatutarios confirmaron o frustraron las expectativas de los coloniales con la República.

\section{EL PREÁMBUlO DEL ESTATUTO COLONIAL: DE LA RENTABILIZACIÓN A LA REPUBLICANIZACIÓN DE LOS TERRITORIOS ESPAÑOLES DEL GOLFO DE GUINEA.}

En los siglos XVI y XVII se esgrimió el discurso misional-civilizador para justificar ocupaciones de territorios en el nuevo mundo; pero en los siglos siguientes el discurso de los conquistadores fue más congruente con los verdaderos fines de los descubrimientos de tierras allende el viejo continente ${ }^{12}$.

10 "La modificación trascendental que en todo nuestro régimen jurídico supone el advenimiento de la República tenía que llegar, en su repercusión, al régimen colonial de los territorios que, formando parte integrante de la soberanía, están sitos en las islas y continente de la Guinea. Era, por tanto, necesario llevar al Estatuto de 1904, para su época, y dentro del aquel régimen progresivo, modificaciones que respondan a estas directrices cuya sola enumeración explica el articulado que las sigue: mayor amplitud para la libertad individual en todas sus manifestaciones, comenzando por la conciencia; democratización gradual de las instituciones y ejercicio de autoridad para ello, influjo prudentemente escalonado de la ciudadanía en la función consultiva, que no deberá ser mera Junta de autoridades; amplia descentralización que otorgue libertad al régimen colonial, aun dadas las mayores facilidades para comunicarse con la Metrópoli; inspección eficaz y directa, que sustituye con ventaja, sobre el terreno, a la injerencia minuciosa y falta de datos y agilidad de los Negociados centrales; disminución de las subvenciones peninsulares y desarrollo de la Hacienda peculiar y fortalecida de Guinea, y selección del personal, cerrando el paso a apetitos y sistemas en que el descrédito sea el mayor de los daños. (Otro párrafo) Tales normas, cuya justificación no parece necesaria, porque basta con su enunciado, inspiran la reforma. Y en virtud de ello, El Gobierno provisional de la República decreta: (Otro párrafo) Para el mejor gobierno y administración de los territorios de Guinea se observarán las siguientes bases: [...]". Véase Agustín Miranda Junco, Leyes coloniales: legislación de los territorios españoles del Golfo de Guinea, op. cit., p. 806

11 Por tal debe entenderse aquella cláusula según la cual, el gobernador, cuando consideraba que peligraba el orden público colonial, podia, discrecionalmente, adoptar cuantas medidas considere necesarias para proteger y garantizar la tranquilidad en los territorios coloniales. Se trata de una cláusula que estaba presente en todos los ordenamientos jurídicos coloniales de todas las potencias colonizadoras.

12 Es opinión de gran parte de los estudiosos que fueron propósitos y fines económicos los que impulsaron la gran empresa colonial. Sólo a modo ilustrativo, puede verse: Aldo Andrea Cassi, Ultramar. L'invenzione europea del nuevo mondo, Laterza, Roma, 2007, p. 10; Lucca. Baccelli, Batolomé de Las Casas. La conquista senza fondamento, Feltrinelli Editore, Milano, 2016, p. 180; Gustavo Gozzi, Diritti e civiltà. Storia e filosofía del diritto internazionale, Il Mulino, Bologna, 2010, p. 13; Alicia Campos Serrano, "Colonia, derecho y territorio en el golfo de Guinea: tensiones del colonialismo español en el siglo XX”, Quaderni Fiorentini, vol. 33-34, 2004/2005, p. 866; 
Según Nogueira Da Silva, a partir del siglo XVIII la cuestión de la legitimidad de la conquista, centro del debate colonial clásico, vino a ser sustituida por la cuestión de la rentabilidad de las colonias ${ }^{13}$. Para el gran colonialista francés Arthur Girault, el éxito de un proyecto colonial, esto es, el logro de la mayor rentabilidad, dependia de la politica y del régimen colonial adoptado en una relación de causa efecto ${ }^{14}$. Sólo una buena política colonial y unas instituciones ajustadas a las particularidades locales podian lograrlo. Los preámbulos de los estatutos anteriores al republicano acusaron este carácter económico-utilitarista que marcó el discurso colonial desde finales del siglo XVIII.

La exposición de motivos del estatuto de 1858 razonaba que el Gobierno, no obstante las dificultades y el esfuerzo que suponía la civilización de los olvidados territorios de Guinea, abrigaba "la voluntad decidida de superarlas, sin retroceder ante sacrificios necesarios y por los cuales espera obtener recompensas" 15 , lo que, a tenor de la tesis de Girault, pasaba necesariamente por establecer en la colonia un régimen y unas instituciones $a d h_{o c}{ }^{16}$. Así lo reconocía el legislador de 1858 al considerar "indispensable dotar a aquellas islas de las autoridades y funcionarios que son el primer fundamento de toda administración, no olvidando que ésta ha de guardar perfecta armonía con las condiciones especiales del país. En Fernando Póo e islas adyacentes, donde las necesidades son escasas, sería inútil aplicar instituciones que suponen grados más altos de civilización, como inconveniente no establecerlas en pueblos más avanzados"17. Los cinco estatutos que siguieron no dejaron de insistir sobre el aspecto económico de la misión civilizadora; en las palabras del legislador colonial de 1904, las reformas aprobadas en Guinea antes de la República iban "encaminadas a transformar los territorios españoles del Golfo de Guinea en una explotación mercantil, cuyo derecho positivo, lejos entorpecer la afluencia de personas y capitales, sirva de incentivo a tan esenciales elementos colonizadores, constituyendo con ellos la base de la prosperidad y riqueza de aquel país"18.

A inicios del siglo XX, vigente en las colonias un régimen laboral cuasiesclavista, el propósito de configurar ese "derecho positivo" que fomentase la afluencia de inversores y demás personas a Guinea era dificilmente conciliable con la mejora de las condiciones laborales de los braceros. Si la colonia parecía un territorio hostil para la salud de los occidentales ${ }^{19}$, no resultaba entones un

Antony Anghie, Martii Koskenniemi, Anne Orford, Imperialismo y derecho internacional, Siglo del Hombre Editores, Bogotá, 2016, pp. 25, 26, 109, 149

13 Cristina Nogueira Da Silva, A Construção Jurídica dos Territórios Ultramarinos..., op. cit., p. 67

14 Samia El Mechat, "Sur les Principes de colonisation d'Arthur Girault (1895)", Revue Historique, $\mathrm{n}^{\circ} 657,2011$, pp. 124-125

15 Agustín Miranda Junco, Leyes coloniales: legislación de los territorios españoles del Golfo de Guinea, op. cit., p. 23 $124-125$

16 Samia El Mechat, "Sur les Principes de colonisation d'Arthur Girault (1895)", op. cit., pp.

17 Agustín Miranda Junco, Leyes coloniales..., op. cit., p. 24

18 Ibidem, p. 138

19 Gonzalo Sanz Casas, Politica colonial y organización del trabajo en la isla de Fernando Poo: 1880-1930, Tesis Doctoral, Universidad de Barcelona (Facultad de Geografia e Historia, Departamento de Antropología Cultural), noviembre de 1983, p. 37 
destino atractivo para aquellos europeos que gozaban de estabilidad económica, incluso minima, en la metrópoli20. A la colonia marchaban quienes no tenían nada que perder, junto con los inversores de "espíritu de cuervo", en atinada expresión de Francisco Madrid ${ }^{21}$. Lógicamente, si algo atraía a estos aventureros era una fortuna fácil y rápida; mas, para conseguirla, no resultaba útil un "derecho positivo" que garantizase a los trabajadores sus descansos y demás derechos laborales ${ }^{22}$. Cuando Ricardo Ferrer investigó el régimen laboral vigente en Guinea al proclamarse la República, el informe resultante no pudo ser más crítico $^{23}$. Según el auditor republicano, ese régimen, al hacer siempre primar el "factor económico" sobre lo humano y lo moral, llevó a una deshumanización del obrero nativo, reducido a la condición de "cosa accesoria a la propiedad", un simple "instrumento" para la maximización del beneficio de los finqueros. A la misma conclusión llegó Gustavo de Sostoa Sthamer, primer gobernador republicano. Tras las observaciones realizadas en su primera gira por el territorio, se pronunció con menos eufemismos y comparó la recluta de braceros con un "mercado de esclavos en el que se comercializa con la mercancía humana conforme a la ley de la oferta y demanda" 24 .

Si los informes de las autoridades republicanas pudieron adolecer de cierta parcialidad por el hecho de valorar la gestión colonial de la recién caída monarquía, no ocurrió lo mismo, sin embargo, con la opinión de los observadores internacionales. La Sociedad de Naciones, tras la adopción de la Convención sobre la Esclavitud de 1926, y en pleno proceso de negociación del convenio sobre el trabajo forzoso (Convenio $\mathrm{n}^{\circ} 29$ de la Organización Internacional del Trabajo), designó tres expertos para investigar denuncias por prácticas esclavistas en Liberia ${ }^{25}$. Según el informe de la comisión (08/09/1930)26, aunque

20 Estanislao Cabanellas, ¡Esclavos! Notas sobre el África negra, Redacción y Administración, Madrid, 1933, p. 9

${ }^{21}$ Francisco Madrid, La Guinea incógnita. Vergüenza y escándalo colonial, Editorial España, Madrid, 1933, pp. 81-82; John Stuart Mill, Representative Government (1861), Batoche Books Limited, Kitchener (Ontario, Canadá), 2001, cap. 18, pp. 197-214

22 Decía Lenin que "el capital financiero no quiere libertad, sino dominación". Véase V. I. Lenin, Obras, Tomo V (1913-1916), Editorial Progreso, Moscú, 1973, pp. 157 y ss.

23 Archivo General de la Administración sito en Alcalá de Henares (en adelante AGA), G-146 (81/6415), expte. $n^{\circ} 133 / 2$, con el escrito (04/06/1932) por el que la dirección general de Marruecos y Colonias envia al gobernador las conclusiones del informe de Ferrer, auditor de la República. En el AGA, las cajas de la sección 15 (fondos sobre África) llevan doble signatura como se muestra en el siguiente ejemplo: G-168 (81/6437). La primera signatura, el número precedido de la "G", indica la posición de la caja en el orden del inventario. Es importante apuntar que las cajas precedentes a la reflejada en el ejemplo no van precedidas de la "G", y serían identificadas, por ejemplo, como sigue: 144 (81/6413). Por su parte, la segunda signatura, el número entre paréntesis, facilita la localización de la caja dentro de la compleja estructura organizativa de los fondos archivísticos. Este ensayo se ajusta a indicadas normas de identificación de las cajas de la sección 15.

24 AGA G-1928 (81/8197), expte. $\mathrm{n}^{\circ}$ 2, diario de la gira del gobernador, entrada correspondiente al 16/04/1932, visita a la delegación de la Curaduría en Bata.

25 Doreen Lustig, The loss of slavery as a humanitarian cause? The League of Nations and the case of Firestone in Liberia,

weblaw.haifa.ac.il/en/Events/IntLborlaw/Documents/Doreen.pdf

26 Report of International Commission of Inquiry into the Existence of Slavey and Forced labor in the Republic of Liberia. (Monrovia, Liberia 8 September; 1930. Commission Members: Dr. 
la esclavitud había desaparecido a tenor de la definición del art.1.1 de la Convención de $1926^{27}$, seguía siendo una realidad bajo formas análogas, como insistía el art.2.b) de la misma Convención. Y en relación a las referidas prácticas esclavistas se abordó el tema de la recluta de braceros liberianos para la colonia española de Fernando Póo. Por cuanto cabe extraer del relato de la comisión, tras finalizar el convenio de 1914 entre España y Liberia, el envío de braceros continuó bajo prácticas progresivamente ilegales. Siempre según el informe, un tal Hoto, un jefe de poblado liberiano, se trasladó a Fernando Póo para observar las condiciones laborales de sus paisanos. Una vez en la isla le impidieron ver a los braceros; pero casualmente encontró un paisano suyo que describió las condiciones de trabajo en las fincas como una "aflicción" ("woe"). Regresado a Liberia, Hoto se negó rotundamente a enviar más trabajadores a la isla española. Tal negativa le acarreó la detención y el encarcelamiento, y los soldados siguieron reclutando a la fuerza a varios muchachos del pueblo. El testimonio de Hoto vale como un ejemplo más entre otros reflejados en el informe de la que se conoció como "Comisión Christy", en honor a su presidente, el Dr. Cuthbert Christy 28.

Parece que el estatuto colonial republicano partió de una nueva ponderación de los valores coloniales. En principio, no se trataba de renunciar a los propósitos económicos de la misión colonizadora; de hecho, cuando la base 13 sostenía que "se emprenderá una política económica que tienda a aumentar los ingresos"29, se estaba declarando el propósito de convertir Guinea en una colonia rentable, aunque esta vez con un matiz importante: en los estatutos precedentes, el factor económico estaba en el centro de todo el proyecto, y el derecho no obedecía a más fin que la atracción de capital y de inversores. En cambio, en el estatuto republicano el objetivo económico se fijaba como un medio más al servicio del factor humano, fin último del proyecto colonial. Cuando las nuevas autoridades declararon que el régimen de Guinea tenía que reflejar los principios republicanos no hicieron sino afirmar aquella humanización y aquella dignificación que hasta entonces había faltado en el trato dispensado a los trabajadores africanos ${ }^{30}$.

Cuthbert Christy, League of Nations, Chairman; Dr. Charles Spurgeon Johnson, United States; Honorable Arthur Barclay, Liberia). Publication $n^{\circ}$ 147; pp. 52-71,

https:// babel.hathitrust.org/cgi/ptid=uiug.30112059732252; view=1up;seq=8

27 Convención sobre la Esclavitud de 25/09/1926; Art.1.1: "La esclavitud es el estado o condición de un individuo sobre el cual se ejercitan los atributos del derecho de propiedad o algunos de ellos", disponible en dipub.org,

ohchr.org/SP/Professionallnterest/Pages/SlaveryConvention.aspx

28 Doreen Lustig, The loss of slavery as a humanitarian cause? The League of Nations and the case of Firestone in Liberia, op. cit.

${ }^{29}$ Rezaba la base 13 del ECR: "A base del estudio de las producciones de la colonia y de la competencia de sus similares extranjeras en España, se emprenderá una politica económica que tienda a aumentar los ingresos, reduciendo progresivamente la subvención de la Metrópoli hasta llegar se a la nivelación del Presupuesto". Véase Agustín Miranda Junco, Leyes coloniales: legislación de los territorios españoles del Golfo de Guinea, op. cit., p. 808

30 Ibidem, p. 806 


\section{ADMINISTRACIÓN DE LOS TTEEGG: ÓRGANOS Y ORGANIZACIÓN TERRITORIAL.}

No es casualidad que el primer estatuto colonial de Guinea date de 1858 . Pues, como sostienen los estudiosos ${ }^{31}$, es entones cuando España ocupó efectivamente los TTEEGG. Pero esa toma de posesión no puede confundirse con el despertar de un verdadero interés por aquellos territorios. En el lapso que discurre entre 1858 y 1904, el gobierno español ensayó varias tácticas para promover la afluencia de colonos a Guinea: pasajes gratis para quienes quisieran instalarse allá; concesiones libres de contribución; subvenciones para la actividad económica; asunción de los costos derivados de la actividad colonial de los misioneros; colonización penitenciaria por la libertad de presos politicos a cambio de trabajar durante cinco años en Guinea; acceso a la propiedad de dichos presos para fomentar su asentamiento en la colonia. La igualdad jurídica declarada en el estatuto de 1868 también puede entenderse en este sentido, ya que suponía algún atractivo para ciudadanos extranjeros ${ }^{32}$. Pese a todos estos incentivos, aunque algunas casas comerciales (sobre todo catalanas) se instalaron en Guinea, lo cierto es que, a la altura de 1904, la presencia española siguió siendo insignificante y concentrada en Fernando Póo, más concretamente en su capital, Santa Isabel.

El legislador pre-republicano no pudo ser más consciente y coherente con el referido panorama. El estatuto de 1904 se alejó de cualquier pretensión ilusa de establecer una compleja división administrativa en una colonia donde más de la mitad de su extensión permanecía prácticamente desocupada. El decreto de 22 de febrero de $1907^{33}$, dictado en desarrollo del art.1 de la Carta colonial ${ }^{34}$, redujo los TTEEGG a cuatro distritos cuya división demarcacional reflejaba con fidelidad los asentamientos españoles. Fernando Póo, primer distrito, quedó dividido en cuatro demarcaciones: Concepción, Moka, San Carlos y Basilé. Santa Isabel, capital de la colonia, quedó comprendida en Concepción. El distrito de Elobey quedó distribuido en tres demarcaciones: Cabo San Juan, Elobey y Asobla; en la segunda demarcación quedaron incluidas las dos islas del mismo nombre y la de Corisco. Por su parte, en la Guinea continental se constituyó el distrito de Nueva Bata, pequeña franja costera que quedó dividida en tres demarcaciones: Campo, Nueva Bata y Benito. El distrito de Annobón no fue

31 Donato Ndongo Bidyogo, Historia y Tragedia de Guinea Ecuatorial, op. cit., pp. 26-32; Gonzalo Sanz Casas, Politica colonial y organización del trabajo en la isla de Fernando Poo: 18801930, op. cit., pp. 13-15, 28; José $\mathrm{M}^{\mathrm{a}}$ Cordero Torres, Tratado elemental de derecho colonial

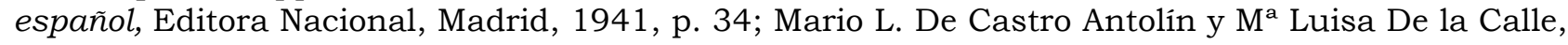
Origen de la colonización española de Guinea Ecuatorial (1777-1860), Universidad de Valladolid, Valladolid, 1992, p. 211

32 Art. 16 del estatuto colonial de 1868: "Disfrutarán iguales derechos para todos los efectos de la ley los indigenas sometidos a España, los nacionales y los extranjeros que se avecinden y arraiguen en dichas posesiones". Véase Agustín Miranda Junco, Leyes coloniales: legislación de los territorios españoles del Golfo de Guinea, op. cit., p. 59

33 Ibidem, pp. 213-214

34 Art. $1^{\circ}$ del RD de 11/06/1904: "Las islas de Fernando Póo, Annobón, Corisco, Elobey Grande y Chico y el territorio continental de Guinea, cuya soberanía quedó reconocida a España por el Tratado con Francia de 27 de junio de 1900, constituirán, para los efectos de sus gobierno y administración, una sola entidad legal, denominada oficialmente "territorios españoles del golfo de Guinea", y dividida en cuatro distritos, a saber: Fernando Póo, Bata, Elobey y Annobón. E1 limite entre los distritos de Bata y Elobey será el río Dote”. 
dividido en demarcaciones. Exceptuando las de Nueva Bata y Elobey, bajo control de dos subgobernadores, en el resto de demarcaciones se establecieron delegados de gobierno que, según sus jurisdicciones, quedaron a las órdenes bien del gobernador, bien de los subgobernadores.

El estado de los asentamientos establecidos en la colonia experimentó un cambio notable entre 1900 y el advenimiento de la República. Bajo los mandatos de Ángel Barrera y de Miguel Núñez de Prado se impulsó la ocupación de la Guinea continental. A través de las llamadas "expediciones de castigo" 35 fueron sometidos varios pueblos del continente, permitiendo así la penetración de la acción civilizacional hasta puntos entonces inexplorados. En las islas, el establecimiento de nuevos asentamientos se manifestó en la sucesiva creación de nuevos consejos de vecinos, como el de Annobón en 1909, el de Batete en 1909, el de Laka en 1927 y el Basakato del Este en 192936. En el continente, los asentamientos coincidieron con la creación de nuevos puestos de la Guardia Colonial en zonas del interior como Niefang, Evinayong, Ayene, Mikomiseng, etc.

Según la base primera del ECR, "las islas de Fernando Póo, Annobón, Corisco, Elobey Grande, Elobey Chico y el territorio continental continuarán denominándose Territorios Españoles del Golfo de Guinea”. La República mantuvo así la denominación oficial introducida por el estatuto anterior, vigente hasta la provincialización de los territorios en 195937. Pero, a diferencia del

35 Miquel Vilaró I Güel, La internacionalización de la SCHUTZTRUPPE. La Guinea Española en la Gran Guerra, Editorial Letras de Autor, Madrid, pp136-146; Gustau Nerín, Un guardia civil en la selva, Editorial Ariel, Barcelona, 2008, p. 224; Fernando Ballano Gonzalo, Politica colonial y organización del trabajo en la isla de Fernando Poo: 1880-1930, op. cit., p. 242-244.

36 Agustín Miranda Junco, Leyes coloniales..., op cit., pp. 274-275, 647, 744.

37 Según Ndongo Bidyogo, en 1935 Guinea pasa a denominarse oficialmente "Territorios Españoles del Golfo de Guinea”. Según Ballano Gonzalo, en 1935 la colonia pasa a llamarse oficialmente "La Guinea Española". Tales afirmaciones deben ser matizadas. La denominación oficial de la Guinea colonial sigue la siguiente cronologia. Todos los estatutos coloniales anteriores a 1904 se refirieron a esos territorios como "Posesiones Españolas del Golfo de Guinea". Desde el estatuto de 1904 hasta la provincialización de dichos territorios en 1959, la denominación oficial de la colonia fue la de "Territorios Españoles del Golfo de Guinea". Con la ley de junio de 1959 se creó la denominada "Región Ecuatorial”, compuesta por dos provincias: Fernando Póo y Río Muni. Esta última incluía, además de la Guinea continental, las islas de Annobón, Corisco, Elobey Grande y Elobey Chico. Así pues, si en 1935 la Guinea se llamaba oficialmente Territorios Españoles del Golfo de Guinea, lo cierto es que la denominación databa de 1904. En relación con la afirmación de Ballano Gonzalo, se usó y siguen los historiadores usando la denominación "Guinea Española”, pero debe advertirse que se trata de una denominación más práctica que legal. Por lo demás, Bartolomé de Las Casas explicó que los árabes del noroeste de África designaban como Guinauha la región donde empezaban los asentamientos de los negros wolof en la actual Mauritania, un territorio que linda con Marruecos y Argelia; de modo que Guinauha significaba sencillamente "tierra de negros". De la degeneración del término los navegantes portugueses extrajeron el topónimo "Guinea", sin perder su sentido original: no es casual que al sur de Mauritania haya varios territorios que comparte nombre (Guinea portuguesa, actual Guinea Bissau; Guinea francesa, Guinea Conakry; en fin y en general, golfo de Guinea). En 1903 los misioneros claretianos fundaron el que llegó a convertirse en el periódico local más relevante: La Guinea Española (1903-1969). Quizá fue se generalizó como topónimo gracias a esta publicación la expresión que le dio título; en cualquier caso es posible que los misioneros adoptaron esa denominación para diferenciar la Guinea bajo soberanía española de la francesa o la portuguesa. Cf. Bartolomé De Las Casas, Brevísima relación de la destrucción de África, Biblioteca Virtual Universal, 2003, cap. VI, párrafo 3, disponible en http://www.biblioteca.org.ar/libros/3064.pdf; Agustín Miranda Junco, Leyes coloniales: legislación de los territorios españoles del Golfo de Guinea, op. cit., pp. 23, 58, 64, 70, 83, 139; 
legislador precedente, la autoridad republicana dividió la colonia en dos distritos: Fernando Póo y Guinea continental. Según el decreto de 13 de abril de 1935, Fernando Póo quedó dividido en Santa Isabel, San Carlos y Basakato del Este. Por su parte, la Guinea continental, más extensa, quedó dividida en diez demarcaciones: Bata, Río Benito (actualmente conocido como Mbini), Kogo, Niefang, Mikomiseng, Ebibeyín, Evinayong, N’Sork, Akurenam, Annobón ${ }^{38}$. En la demarcación territorial de Kogo quedaron también incluidas las tres islas menores: Corisco, Elobey Grande y Elobey Chico.

Al frente de la administración colonial se situaba la figura del gobernador, máximo representante de la República en la colonia. Como tal, el estatuto establecía que "le estarán subordinados todos los funcionarios de la colonia" (base $2^{\mathrm{a}}$ ). Los republicanos respetaron asi un principio clave del ius commune colonial: si el gobernador era el eje de la colonia, el resto de órganos e instituciones no constituían sino una estructura auxiliar a su alrededor ${ }^{39}$. Su nombramiento se hacía libremente por el consejo de ministros, a propuesta del presidente (base $2^{\mathrm{a}}$ ). Igual que en el anterior estatuto, el ECR silenció la duración del mandato y el carácter militar de dicho cargo ${ }^{40}$. Pero, a diferencia del estatuto de 1904, en el ECR tal silencio tuvo distintas interpretaciones según las materias omitidas. En el caso de la duración del cargo, aunque parece lógico que los republicanos mantuvieron el mandato bienal establecido en los estatutos precedentes, la práctica reveló que se decantaron incluso por un mandato más breve. En los seis años que duró la República en Guinea (14/04/193114/10/1936), si exceptuamos a quienes ejercieron el cargo como interinos ${ }^{41}$, se sucedieron cuatro gobernadores oficiales; ninguno llegó a cumplir dos años de mandato $^{42}$. Respecto del carácter militar del cargo, el silencio del ECR significó

Fernando Ballano Gonzalo, Aquél negrito del África tropical..., op. cit., p. 426; Donato Ndongo Bidyogo, Historia y tragedia de Guinea Ecuatorial, op. cit., p. 46

38 Advertimos que la nomenclatura presentada en el cuerpo del texto es a empleada actualmente. La utilizada en la norma en la referida norma colonial es la siguiente: Bata, Río Benito, Kogo, Niefan, Mikomesén, Ebebiyin, Ebinayong, N’Sork, Akurenan, Annobón.

39 Pierre Guillaume, Le Monde Colonial. XIX-XX Siècle, Librairie Armand Collin, Paris, 1974, p. 140 y ss; Santi Romano, Corso di diritto coloniale impartito nel R. Istituto di scienze social $C$. Alfieri di Firenze, Athenaeum, Ferrara, 1918, p. 159

40 Antes del estatuto colonial de 1904 podía ser designado gobernador de los TTEEG sólo una autoridad militar. Desde el primer estatuto de 1858 los rangos que más se repetían entre los gobernadores coloniales eran los de capitán de navío de primera o segunda clase, teniente de navio de primera clase, capitán de fragata. Véase Gonzalo Álvarez Chillida, "Los Gobernadores de Fernando Poo (1858-1930)", en Luis Jean-Philippe, L'Ėtat dans ses colonies. Les administrateurs de l'Empier espagnol au XIX siècle, Collection de la Casa de Velázquez, Madrid, 2015, p. 159

41 José Domínguez Manresa actuó de interino en dos ocasiones, primero bajo con Núñez de Prado tras la proclamación de la República y hasta la toma de posesión de Gustavo de Sostoa (noviembre de 1931) y nuevamente desde el asesinato de Sostoa hasta julio de 1933. Pedro Agustín González Ordóñez fue interino con Sostoa. Luis Serrano Moranges lo fue en dos ocasiones: con Lluesma en 1934 y entre junio de 1935 y diciembre de 1935; pero también entre setiembre de 1926 y enero de 1937. Finalmente, Carlos Vázquez Ruiz ejerció como interino con Luis Sánchez Guerra entre marzo y abril de 1936. Para todo esto, cf. La Guinea Española, no 671, 26/07/1931, p. 239; La Guinea Española, $\mathrm{n}^{\circ} 680,13 / 09 / 1931$, p. 296; La Guinea Española, $\mathrm{n}^{\circ}$ 941, 27/09/1936, p. 301

42 Gustavo de Sostoa Sthamer (04/08/1931 - 14/11/1932); Estanislao Lluesma García (mayo de 1933 - setiembre de 1934); Ángel Manzaneque Feltrer (setiembre de 1934 - diciembre de 1935); Luis Sánchez Guerra y Sáinz (07/09/1935 - setiembre de 1936). Sobre estos particulares, 
un claro rechazo al pasado. Con la República llegó el primer civil al gobierno de la colonia: el mencionado Gustavo de Sostoa ${ }^{43}$ quien, desafortunadamente, terminó siendo asesinado por el cabo Restituto Castilla en Annbón el 14 de noviembre de $1932^{44}$. No obstante este trágico incidente, y aunque los dos gobernadores siguientes procedian de la carrera militar ${ }^{45}$, la República no renunció por completo a nombrar civiles al frente del gobierno colonial. De hecho, tanto el último gobernador republicano, Luis Sánchez Guerra, como el último subgobernador, Miguel Hernández Porcel, no habian seguido la carrera militar: el primero era ingeniero de caminos $^{46}$ y el segundo, ingeniero agrónomo ${ }^{47}$.

Respecto del equipo de funcionarios que asistian al gobernador en su gestión, el estatuto general de los funcionarios coloniales, siempre en desarrollo del ECR, estableció una clasificación funcionarial en función del tipo de nombramiento y de los requisitos exigidos para acceder a los distintos puestos de la Administración. Partiendo de estos criterios clasificatorios, con respeto a la jerarquía administrativa, distinguimos al secretario general $y$ a los

véase decreto de 4 de agosto de 1931 por el que se admite la dimisión de Miguel Núñez de Prado como gobernador general de los TTEEGG (Gaceta de Madrid, n 218, 06/08/1995, p. 995); decreto de 4 de agosto de 1931 por el que se nombra a Gustavo de Sostoa y Sthamer como gobernador general de los TTEEGG (Gaceta de Madrid, n 218, 06/08/1995, p. 995); decreto de mayo de 1933 por el que se nombra gobernador general de los TTEEGG a Estanislao Lluesma y García (Diario ABC, $n^{\circ}$ de 07/05/1933, p. 53); decreto de 7 de septiembre de 1935 por el que se admite la dimisión de Ángel Manzaneque Feltrer (Gaceta de Madrid, n ${ }^{\circ}$ 251, de 08/09/1935, p. 1946; cf. ABC, $n^{\circ}$ del martes 10/09/1935, p. 24); decreto de 7 de septiembre de 1935 por el que se nombra gobernador general de los TTEEGG a Luis Sánchez Guerra y Sáinz (Gaceta de Madrid, $\mathrm{n}^{\circ}$ 251, de 08/09/1935, p. 1946; cf. ABC, $\mathrm{n}^{\circ}$ del martes 10/09/1935, p. 24 ); La Guinea Española, no 673, de 09/08/1931, p. 252-254; La Guinea Española, n ${ }^{\circ}$ 680, de 27/09/1931, p. 310; La Guinea Española, n ${ }^{\circ}$ 682, de 04/10/1932, p. 314; La Guinea Española, n 833, de 02/09/1934, p. 278; La Guinea Española, nº 887, de 15/09/1935, p. 265

43 Un breve curriculum del gobernador se publicó en Luz. Diario de la República, n 269 de $15 / 11 / 1932$, pp.15-16

44 Gustau Nerín, "Socialismo utópico y tiranía: La isla de Annobón bajo el cabo Restituto Castilla (1931-1932)", Afro-Hispanic Review, vol. 28, n 2, 2009, pp. 311-330; La Guinea Española, n 740 de 15/11/1932, página única; La Guinea Española, no 741 de 20/11/1932, p. 367

$45 \mathrm{El}$ difunto Gustavo de Sostoa fue sucedido oficialmente por Estanislao Lluesma y García, coronel médico de la Armada. Véase La Guinea Española, nº 765, de 14/05/1933, p. $136 . \quad$ El sucesor oficial de Lluesma fue Ángel Manzaneque Feltrer, que pertenecia al Cuerpo Jurídico Militar. Véase La Guinea Española, n 833, 02/09/1934, p. 278; La Guinea Española, n 834, de 09/09/1934, página de portada.

46 Sánchez-Guerra era hijo de politico conservador José Sánchez-Guerra, ministro de Fomento entre 1907 y 1909. Estudió Ingeniería de Caminos, finalizando 1914. Tomó parte en la construcción de los puertos de Alicante y de Santa Isabel. En noviembre de 1935, fue nombrado Gobernador de los TTEEGG, cargo que ocuparia efectivamente en diciembre del mismo año. Véase: Miguel Ángel Pozanco, Guinea Mártir: narraciones, notas y comentarios de un condenado a muerte, Editor Colección Actualidad, Madrid, 1937 p. 84; Manuel Burgos Madroñero, Crónicas portuguesas de la Guerra Civil de España: os informes del Vicecónsul portugués en Fernando Poo, Revista Alaba, n³1, 2001, p. 89; La Guinea Española, n 887, de 15/09/1935, p. 265; La Guinea Española, no 898, 01/12/1935, p. 359; decreto de 07/09/1935 por el que se nombra gobernador de los TTEEGG a Luis Sánchez Guerra y Sáinz (Gaceta de Madrid, no 251, de 08/09/1935).

47 Miguel Ángel Pozanco, op.cit., p. 84; La Guinea Española, nº 896, de 17/11/1935, p. 342; decreto de 04/11/1935 por el que se nombra subgobernador de la Guinea continental Miguel Hernández Porcel (Gaceta nº 310 de 06/11/1935). 
subgobernadores. Antes de la aprobación del estatuto de la Administración local de 13 de abril de 1935, todos esos cargos eran nombrados libremente por el presidente del consejo de ministros (base $3^{\mathrm{a}}$ del ECR y art. $2.2^{\circ}$ del estatuto de funcionarios coloniales). Tras la referida reforma, el acceso al cargo de secretario pasó a ser mediante concurso de méritos entre funcionarios que, además de ser letrados de la Administración, no podian tener más de cuarenta y cinco años edad (base $3^{a}$ del Estatuto de la Administración Local). La misma reforma de 1935 estableció que el secretario, además de su antigua función de sustituir al gobernador en sus ausencias y enfermedades, pasara a ser formalmente jefe de todos los servicios administrativos de la colonia. En relación con el cargo de subgobernador, la reforma sólo hizo una corrección al ECR. Aunque la República designó siempre a un subgobernador para la Guinea continental, la base $3^{a}$ del ECR, al hablar de "subgobernadores" en plural, parecía sugerir el mantenimiento de la práctica precedente, consistente en designar un subgobernador con sede en Bata y otro con sede en Elobey. Pues la reforma de 1935 concilió la forma y la realidad en este sentido, estableciendo un único subgobernador para toda la parte continental (base $4^{\mathrm{a}}$ del Estatuto de la Administración Local).

Un segundo bloque funcionarial reunió a aquellos administrativos cuyos cargos, por su especialidad, requerian sujetos procedentes de "cuerpos o carreras de España". Dentro de este grupo, unos eran nombrados por libre elección del presidente del consejo de ministros (o por la Dirección General de Marruecos y Colonias ${ }^{48}$ ) a propuesta de sus cuerpos de procedencia; por ejemplo el jefe de la Policía Gubernativa, el de la Guardia Colonial o el capitán del puerto de Santa Isabel. Otros funcionarios del mismo grupo accedian por vía de concurso; era el caso de los llamados jefes de servicios coloniales (jefe o director del Servicio Sanitario, jefe del Servicio Agrónomo, jefe del Servicio Forestal, jefe o director de la Administración Principal de Hacienda y Aduana, inspector de Enseñanza, etc.).

Un tercer colectivo de funcionaros agrupaba a todos aquellos cuyos cargos exigian la posesión de título facultativo. Eran nombrados por el presidente del consejo de ministros (o por la recordada Dirección General) por concurso o por concurso-oposición. Como ejemplos de este tipo tenemos al juez de Primera Instancia e Instrucción de Santa Isabel, el registrador de la propiedad y los médicos, farmacéuticos, enfermeros y demás auxiliares técnicos del Servicio Sanitario.

\section{COMPETENCIAS LEGISLATIVAS DEL GOBERNADOR}

Según la base $2^{a}$ del ECR, el gobernador "publicará, ejecutará y hará que se ejecuten todas las disposiciones emanadas del Gobierno de la República y dictará las instrucciones necesarias para su inmediato y debido cumplimiento". En la misma línea, la base $14^{a}$ atribuía al ejecutivo metropolitano la facultad reglamentaria y la facultad de adaptar las leyes a las particularidades de los

48 La Dirección General de Marruecos y Colonias (DGMC) era una administración intermediaria entre la presidencia del gobierno y la administración de tanto del protectorado como de las colonias. Tal organismo se sometía directamente a la presidencia del gobierno, actuado principalmente como delegada de ésta en la gestión del protectorado y de las colonias. Fue creada en 1925. 
territorios coloniales. Como se extrae de estas disposiciones, el gobierno español era el legislador colonial; al gobernador le correspondia decidir los pormenores relativos a la aplicación de las normas previamente dictadas desde la metrópoli. Pero este reparto de competencias entre el gobierno central y el colonial debe entenderse sólo en el plano formal; si en algo coinciden los críticos del colonialismo es, precisamente, en situar a los gobernadores coloniales como los verdaderos legisladores de las colonias. En otras palabras, los ejecutivos centrales, una vez aprobadas las normas, dejaban su ejecución y aplicación bajo control absoluto de la autoridad colonial.

Según el art. 1 del estatuto de 1888, el gobernador "será responsable de la conservación y defensa de dichas posesiones. A este fin, disfrutará de las atribuciones, asi ordinarias como extraordinarias, que las leyes vigentes confieren a las autoridades Superiores de Ultramar"49. Parece que al legislador le resultó insuficiente hablar sólo de "atribuciones ordinarias y extraordinarias" y tuvo que incluir un criterio interpretativo, aclarando que el alcance de estos poderes era el mismo que el de las facultades de las autoridades superiores de Ultramar. ¿Qué poderes o facultades ejercían los superiores de Ultramar? Petit50 estudió las atribuciones de los gobernadores de Guinea y su definición no coincide precisamente con la de unos administradores limitados a ejecutar y aplicar las leyes metropolitanas. Según Petit, el gobernador ejercía amplísimas atribuciones, concentrando los tres poderes. Josep Fradera, en la misma linea que Petit, matiza que era tan absoluto el poder de los gobernadores ultramarinos que era casi imposible distinguir leyes fuera de su voluntad ${ }^{51}$. Según Bartolomé Clavero ${ }^{52}$, citando también a Petit, constituía una arbitrariedad en sí el hecho mismo de dejar en manos del ejecutivo central la aprobación de las leyes especiales para Ultramar. Pero dicha arbitrariedad podía considerarse leve en comparación a la producida en el momento de aplicar dichas leyes especiales. La colonia era considerada como una gran familia, un espacio sobre el que se proyectaba la sombra del gobernador, celebrado paterfamilias ${ }^{53}$. Éste decidía qué normas habría que aplicar en la colonia, cómo interpretarlas y cómo aplicarlas; decidia las modificaciones que creía convenientes sin necesidad de retocar

49 Agustín Miranda Junco, Leyes coloniales: legislación de los territorios españoles del Golfo de Guinea, op. cit., p. 83

50 Carlos Petit, "Detrimentum Rei Publicae", en José M ${ }^{\mathrm{a}}$ Iñurritegui y otros (eds.), Constitución en España. Orígenes y destinos, Centro de Estudios Politicos y Constituciones, Madrid, 1998, pp. 425-494

51 Desde la Constitución española de 1837 se adoptó el principio de la legislación especial para las provincias de Ultramar. Como se sabe el artículo adicional $2^{\circ}$ establecía que "Las provincias de Ultramar serán gobernadas por leyes especiales". Fradera critica tanto el carácter discriminatorio de esta disposición como la poca voluntad que hubo por parte del gobierno en hacer respetar las pocas leyes que se aprobaron para Ultramar ("no fue así, a las colonias no se las dio ni ese triste consuelo: se las dejó sin "leyes", a expensas de la arbitrariedad de los Capitales generales... Dicho con máxima concisión posible: las leyes especiales eran la ausencia de leyes especiales", en Josep $\mathrm{M}^{\mathrm{a}}$ Fradera, Colonias para después de un imperio, Editorial Bellaterra, Barcelona, 2005, pp.163-164; también, del mismo, Gobernar Colonias, Editorial Peninsula, Barcelona, 1999, pp. 93

52 Bartolomé Clavero, "Bioko, 1837-1876: Constitucionalismo de Europa en África, derecho internacional consuetudinario del trabajo mediante”, op. cit., pp. 440, 532

53 Ibidem pp. 487, 492, 530 
siquiera la letra de la ley ${ }^{54}$. En fin, como bien recuerda Clavero, los poderes del gobernador no podian ser reducidos por escrito.

El absolutismo de esas autoridades no fue una peculiaridad del colonialismo español. Cuando Petit describe un "ius publicum europaeum" 55 construido en el Berlín de 1885 y cuando Clavero habla de un uius commune colonial "56, se refieren precisamente a aquellos principios sobre los que se levantó la teoría o filosofia del colonialismo, presentes, mutatis mutandis, en todos los sistemas de colonización. En el Travail sur l'Algérie de Alexis de Tocqueville, se puede observar que la situación de la Argelia colonial no había sido muy distinta a la de las colonias españolas ${ }^{57}$. En Argelia regía un derecho de excepción; la administración colonial, civil o militar, era por esencia opresora. No existian libertades constitucionales; y aunque fuesen reconocidos unos mínimos derechos, su ejercicio impactaba contra el poder absoluto del gobernador. Titular del mando supremo de las fuerzas militares, el gobernador juzgaba soberanamente como el rey en la metrópoli ${ }^{58}$ y ejercía la potestad reglamentaria, aprobando disposiciones en casos de urgencia y necesidad. Según Tocqueville, si bien el ejercicio de esta facultad reglamentaria se previó como una excepción, en la práctica fue la regla general, erigiendo así a los gobernadores en los verdaderos legisladores coloniales. Según Pierre Guillaume 59 , en las colonias francesas el gobernador era "responsable du maintien de l'ordre", y como tal, depositario de los poderes de la República. Como jefe del ejecutivo disponía de las fuerzas armadas y nombraba, suspendía y cesaba a los funcionarios ${ }^{60}$. Como titular del poder legislativo, podía impedir la aplicación de leyes metropolitanas y ejercía la potestad reglamentaria dictando disposiciones que se consideraban una "véritable législation spécifique". También controlaba el poder judicial. Guillaume recuerda que el absolutismo de los gobernadores coloniales fue común a todos los imperios coloniales.

Los politicos republicanos también consideraron conveniente asegurar cierta libertad de actuación al gobernador de Fernando Póo para los casos en que peligrase el orden público o la seguridad en la colonia. Para ello, el tercer párrafo de la base $2^{a}$ del ECR estableció que esa autoridad "tomará cuantas medidas considere necesarias para conservar la seguridad de los territorios,

54 Ibidem p. 529

55 Carlos Petit, "Detrimentum reipublicae”, op. cit. pp. 513-515

56 Bartomé Clavero, “Bioko, 1837-1876: Constitucionalismo de Europa en África, derecho internacional consuetudinario del trabajo mediante”, op. cit., pp. 513, 515

57 Alexis De Tocqueville, Travail sur l'Algérie (1841), Université du Québec à Chicoutimi, Les Classiques des Sciences Sociales, disponible en el link:

http://classiques.uqac.ca/classiques/De_tocqueville_alexis/de_colonie_algerie/travail_sur_alg erie/travail_sur_algerie.html

58 "En Algérie c'est le gouverneur général qui juge souverainement les conflits, de même que le roi le fait en France". Ibidem, p. 46

59 Pierre Guillaume, Le Monde Colonial. XIX-XX Siècle, op. cit.

60 "Nous avons vu que, responsable du maintien de l'ordre, le gouverneur a, dans tous les empires coloniaux, un très large pouvoir réglementaire, qui lui permet, d'une part de ne pas étendre automatiquement à son territoire les lois métropolitaines, d'autre part d'édicter une véritable législation spécifique”. Ibidem, p. 158 
informando de ellas"61. Es lógico pensar que la disposición se inspirase en el art. 4.3 del estatuto de 1904 y no en los equivalentes preceptos de los estatutos anteriores. Si el régimen colonial tenía ahora que ser un reflejo de los valores republicanos, como rezaba el preámbulo del ECR, entonces convenía evitar el uso de giros o expresiones inconciliables con los principios de la democracia republicana. Giros como "poderes discrecionales", "atribuciones extraordinarias" o "facultades de los Superiores de Ultramar", todos utilizados en los estatutos anteriores a 1904, evocaban al descrito poder fáctico y absoluto que siempre detentaron los gobernadores coloniales, tan contrario al espiritu de libertad que inspiró al constituyente de 1931. Ahora bien, que los republicanos hubiesen evitado una terminología autoritaria en el párrafo tercero de la base $2^{\text {a }}$ del ECR no implicó automáticamente una interpretación restrictiva del margen de discrecionalidad concedido al gobernador de Fernando Póo para salvaguardar el orden público colonial. Al contrario, las facultades que reconocía este precepto eran las mismas que ejercian los antiguos gobernadores sobre la base de las "atribuciones extraordinarias" que les reconocian expresamente los estatutos. Prueba de ello fue que, después que las 'informaciones' de Ferrer ${ }^{62}$ confirmaran muchas de las arbitrariedades denunciadas bajo el mandato de Núñez de Prado, la República exigió responsabilidad a varios de sus colaboradores ${ }^{63}$, pero nunca a éste mismo64. Como bien razonó el auditor en una de las informaciones tramitadas ${ }^{65}$, Núñez de Prado, como máximo responsable de la seguridad y de la paz en la colonia, tenía reconocidas atribuciones especiales que, precisamente, ampararon muchas de las medidas y decisiones que adoptó durante su mandato.

El 2 de noviembre de 1932 Ángel Rubio, diputado por Cáceres, planteó en las Cortes una petición en nombre y defensa del doctor Juan García Bote, un funcionario de Guinea que, según Rubio, había sido víctima de los poderes arbitrarios de Gustavo de Sostoa ${ }^{66}$. La cuestión de fondo sigue revelando los amplios poderes que detentaba el gobernador general a la hora de aplicar las normas coloniales. Según el art. 12 del estatuto de los funcionarios coloniales, año y medio de servicio en la colonia daban derecho a una licencia de seis

61 Agustín Miranda Junco, Leyes coloniales..., op. cit., p. 807

62 En la colonia el término hacía referencia a los expedientes tramitados ya fuera para investigar una irregularidad administrativa, ya para investigar un delito. De modo que "abrir una información" era sinónimo de "abrir un expediente".

63 Algunos fueron cesados a causa de dichas investigaciones, como García Loygorri, subgobernador de Bata, implicado en la recluta de braceros; Enrique Mené, acusado de asesinar a dos indigenas; David Carillo; Eugenio Touchard... Véase Gustau Nerín, Un Guardia Civil en la selva, op. cit., pp. 229-230

64 Según Nerín, después de la proclamación de la República Núñez de Prado fue convocado a Madrid; tan pronto como manifestó su firme adhesión al nuevo régimen la izquierda hizo de todo para ocultar los escándalos del gobernador; la misma presidencia de la República intervino paralizando los expedientes tramitados en su contra. Véase también Fernando Ballano Gonzalo, Aquél negrito del África tropical..., op. cit., p.386

65 AGA G-179 (81/6448), expte. tramitado entre el 07/08/1931 y el 22/08/1931 para investigar las intromisiones de Núñez de Prado en el funcionamiento de la administración colonial.

66 Diario de sesiones de las Cortes, sesión 02/11/1932, pp. 9223 y ss. 
meses $^{67}$. En febrero de 1932 la dirección general de Marruecos y Colonias adoptó una disposición según la cual "no se podrá disfrutar de licencias que taxativamente concede el estatuto de funcionarios, en su art. 12, sin que, a juicio del gobernador general, queden cubiertas las necesidades administrativas coloniales y que el número de funcionarios ausentes no pueda exceder de la tercera parte de los asignados a cada servicio". El 7 de agosto de 1932 el Dr. Bote publicó un artículo en el periódico El Defensor de Guinea, subrayando la contradicción existente entre las normas en cuestión. El gobernador consideró el artículo una injuria hacia su persona. Además de llamar la atención al director del periódico por publicarlo, convocó la junta de autoridades para abordar el caso. La mayoría consideró que las críticas del Dr. Juan Bote iban contra una disposición, sin dirigirse a persona determinada. Pero, pese al parecer de la Junta, el gobernador, alegando necesidades de servicio, ordenó el traslado de Bote a la estación sanitaria de Niefang68. Parece que, legalmente, esa vacante no debía cubrirla el médico, ya que, tratándose de un hospital de segunda, tenía que ser atendido por un médico de la misma categoría y no por un médico de primera, como era Bote. Pese a esta irregularidad, y pese a disponerse de otros médicos, el gobernador lo envió a Niefang. El afectado recurrió la decisión ante la dirección general ${ }^{69}$, que se manifestó impotente ante la decisión del gobernador. El diputado Rubio pidió a las Cortes declarar la primacía del estatuto de los funcionarios sobre la citada disposición de la dirección general; la misma, alegó Rubio, concedia "facultades excesivas" al gobernador, sujetando a su arbitrio el ejercicio del derecho reconocido en el art. 12 del estatuto de funcionarios. Pero la moción de Rubio ni siquiera abrió un debate que mereciera atención.

Como se dijo antes, el control absoluto que ejercian los gobernadores sobre la efectividad de la norma no se daba solamente al momento de aplicarla en el territorio; también aparecía en su aprobación misma. Cuando una disposición dictada en la metrópoli podía poner en riesgo la tranquilidad y el estado de cosas vigente, el gobernador estaba capacitado para impedir su recepción en la colonia. Por ejemplo, los gobernadores se negaron a extender el Código Penal de

67 "Todo funcionario tendrá, cada dieciocho meses, derecho a seis meses de licencia reglamentaria, en los que estará incluido el tiempo necesario para efectuar los viajes de ida y vuelta a España... El funcionario percibirá durante la licencia reglamentaria de seis meses el sueldo y sobresueldo íntegros. Estas licencias podrán prorrogarse por dos meses en caso de enfermedad plenamente comprobada a satisfacción de la Dirección General de Marruecos y Colonias, de tal anticipación que, en caso denegarse, pueda el funcionario presentarse en su puesto a terminar los seis meses de licencia no prorrogada... Por delegación especial permanente de la Dirección General estará el Gobernador general facultado para conceder estas licencias reglamentarias que se solicitarán por conducto del Jefe de Servicio y con el informe de éste. En ningún caso podrán concederse estas licencias sin que el funcionario lleve dieciocho meses completos de servicio en su puesto". Véase Agustín Miranda Junco, Leyes coloniales: legislación de los territorios españoles del Golfo de Guinea, op. cit., p. 822

68 Es una ciudad del interior de la parte continental de Guinea Ecuatorial. Se encuentra a $70 \mathrm{~km}$ de Bata, capital de la Región Continental. Durante el periodo colonial, se conoció como Sevilla de Niefang.

69 La Dirección General de Marruecos y Colonias se creó en 1925 como eslabón entre el gobierno central y las administraciones coloniales. Véase Javier Alvarado Planas y Juan Carlos Domínguez Nafría, La Administración del Protectorado Español en Marruecos, BOE, Madrid, 2014, pp. 120-125 
1929 a Guinea ${ }^{70}$, o la Convención Internacional sobre la represión de la trata de mujeres mayores (Ginebra, 11/10/1933)71, o, finalmente, el estatuto de los refugiados alemanes que no gozaban de la protección del Reich (Ginebra, 04/07/1936) ${ }^{72}$. La otra posibilidad suponía admitir la extensión de la norma metropolitana pero bajo las condiciones particulares que regirian su aplicación local; tal fue el caso del convenio $\mathrm{n}^{\circ} 29$ de la Organización Internacional del Trabajo (Convenio sobre el Trabajo Forzoso, 1930), cuya aplicación en Guinea según las autoridades coloniales requería un periodo transitorio más largo que el previsto para la metrópoli73.

Después de lo dicho en los párrafos precedentes sobre la potestad normativa del gobernador general se puede concluir con la afirmación de partida. Si la base $14^{\mathrm{a}}$ y el párrafo segundo de la base $2^{\mathrm{a}}$ convertian al Ejecutivo central en legislador colonial formal, el párrafo $3^{\circ}$ de la misma base permitía al gobernador ejercer un control absoluto sobre la aplicación del régimen jurídico colonial. Tenía su lógica la fórmula. Como se dijo en las Constituyentes, en la colonia la seguridad y el orden público se hallaban en una situación delicada; vincular el gobernador general a formalismos dictados a miles de millas no hacía sino restar la inmediatez que debía caracterizar su actuación. En rigor, el gobernador actuaba como el paterfamilias de la gran familia colonial. Si conocía su realidad in situ y era responsable de mantener el orden público, entonces había que reconocerle "una gran amplitud de medios", según afirmó Santiago Alba en las Cortes ${ }^{74}$. Precisamente, el párrafo $3^{\circ}$ de la base $2^{a}$ ERC le reconocía semejante "gran amplitud de medios". Pero la ambigüedad de esta disposición hizo difícil la distinción entre la voluntad del gobernador y las normas coloniales. El citado párrafo $3^{\circ}$ no especificaba cuáles eran las "medidas necesarias" que podía adoptar el gobernador, limitándose a prever una tímida garantía al ordenar que las adoptadas se comunicaran al gobierno central. Sin embargo, de la comunicación no se derivaba ni una revisión, modificación o suspensión de las medidas ni una anulación de las decisiones ya tomadas por la autoridad colonial. Como puede observarse, con aquella disposición a la mano el gobernador general asumía la función de un auténtico legislador. A su autoridad

70 "Claro está que se propone la aplicación con diferentes reformas; pero aceptar unos preceptos y otros no, desarticulando el código, le quita estructura y armonía... le convertiría en una de aquellas compilaciones sin unidad, de los tiempos jurídicos pasados". Véase AGA, G-211 (81/6480), expte. $n^{\circ} 198 / 3$, resolución de 08/06/1929 de la Junta de Asuntos Judiciales de la Dirección General de Marruecos y Colonias.

71 AGA 86 (81/6355), informe nº 508 del gobernador de 16/07/1934

72 De la caja precedente, comunicado del subsecretario del gobierno colonial de $10 / 10 / 1936$.

73 "El atraso del indigena ha de ser causa de que el período de transición que conduzca a la supresión absoluta del trabajo obligatorio no sea tan breve como en la metrópoli y de que, en algunas ocasiones, la ley no tenga la aplicación restringida que fuera de desear del mejoramiento y progreso en general de aquella población autóctona, debiendo hacer presente a V.E. que por el Gobierno de Guinea se procura remunerar el trabajo del indigena aún en el caso de ser forzoso; nuestra acción colonial no puede tampoco sustraerse el ritmo seguido por los demás países colonizadores en el África occidental, cuyos procedimientos, por cierto, en lo que se refiere al trato de indígena, no son mejores que los nuestros, -peores muchas veces-". Véase AGA G-1910 (81/8179), expte. $n^{\circ} 5$, escrito de 15/07/1932 emitido por la sección de colonias de la dirección general de Marruecos y Colonias.

74 Diario de sesiones de las Cortes, sesión de 01/12/1931, p. 2754 
correspondía valorar libremente cuándo peligraba la paz y el orden público, y tomar las disposiciones que juzgare más convenientes. Con ese fin podia ejercer tanto su potestad reglamentaria como sus poderes fácticos para alterar las normas vigentes; podía suspender su aplicación y cumplimiento ${ }^{75}$ y podía matizar o negar la extensión a la colonia de normas metropolitanas y de los convenios internacionales ratificados por España.

\section{COMPETENCIAS SANCIONADORAS DEL GOBERNADOR GENERAL}

Según el estatuto de 1904 el gobernador no sólo podía "suspender, por causa justificada en expediente, a los funcionarios de la Administración cuyo nombramiento corresponda al Gobierno, dando a éste inmediata cuenta" (art.4. $\left.9^{\circ}\right)^{76}$, sino que también, de forma general, tenía la facultad de "dictar bandos para corregir faltas; mantener el sosiego público y para fines de policía y buen gobierno dentro de los limites, en la penalidad, señalados por el Ministerio de Estado" (art.4. 12\%). El ECR reprodujo la disposición de ese art.4. 9º pero el último párrafo de la base $14^{\mathrm{a}}$ del ECR ordenó que "salvo precepto expreso en contrario, no se admitirá recurso de alzada contra resoluciones del Gobernador". El estatuto de 13 de abril de 1935, primera refundición del ECR no subsanó la omisión y mantuvo expresamente la vigencia del Estatuto refundido en lo que fuere compatible con el nuevo texto. Lo mismo cabe decir de la segunda refundición, operada por el decreto de 14 de noviembre de 1935, que, tras reproducir el ECR en su integridad, terminó declarando su derogación. Pese a este silencio (consciente) del legislador, la facultad sancionadora de los gobernadores republicanos estuvo fuera de duda. Estos, igual que sus antecesores, no sólo aplicaban o ejecutaban las sanciones establecidas por el Ejecutivo central; también gozaban del poder para dictar normas con sanciones que iban de la simple multa a la expulsión de la colonia, pasando por la clausura de establecimientos, el decomiso de bienes, la retirada de autorizaciones comerciales, la prohibición de contratar braceros, incluso la prisión.

Aunque la facultad sancionadora de los gobernadores se encontraba implicitamente amparada en el poder discrecional que les reconocía la base $2^{\mathrm{a}}$ del ECR para conservar el orden público colonial, de la interpretación de las autoridades centrales se deduce que esta competencia se fundamentó principalmente en la delegación de poderes presidenciales al gobernador colonial. El 29 de septiembre de 1934, presionado quizá por los escritos elevados a las Cortes por Julio Moreno Dávila 77 y Juan Palomino ${ }^{78}$ en defensa de Jesús

75 El art.4 del estatuto orgánico colonial de 1904, entre las facultades que reconocía al gobernador establecía estaba la de " $2^{\circ}$ Suspender la publicación y cumplimiento de las disposiciones que le comunique el ministerio de estado cuando, su juicio, pudieran causar daño a los intereses generales de la Nación o a los especiales de los territorios de su mando, de que dará, sin pérdida de momento, cuenta razonada a dicho ministerio", y la de "40 Proponer el indulto de la toda clase de penas y suspender la ejecución de la muerte". Ambas disposiciones fueron asumidas por el Estatuto colonial republicano, ya que éste no derogó expresamente el Estatuto de 1904.

76 Agustín Miranda Junco, Leyes coloniales..., op. cit., p. 139

77 El escrito presentado por Dávila en la sesión de las Cortes de 4 de abril de 1934 recordaba que "los territorios españoles del Golfo de Guinea dependen directa y exclusivamente en su régimen y administración de la Dirección General de Marruecos y Colonias, teniendo al frente de las posesiones a un gobernador general libremente nombrado, con amplísimas y 
discrecionales facultades para el gobierno de las colonias. Pero lo que no puede consentirse es que abusando el representante del Poder central de unas facultades no regladas ocasione perjuicios irreparables a los españoles que han tenido el patriotismo de llevar a nuestras posesiones sus familias e intereses, que han montado un negocio, para contemplar cómo un gobernador, porque sí, impone multas caprichosas, decreta el comiso de mercancias, arruina, en suma, a industriales que no han cometido más delito que discrepar de las ideas políticas del Gobierno... En el "Boletín Oficial" de los territorios españoles del Golfo de Guinea se publicó el día $1^{\circ}$ de Octubre un decreto, firmado por el gobernador general Sr. Lluesma, reglamentando la venta de bebidas alcohólicas... Dicho decreto fue recibido con desagrado por todo el comercio de la colonia porque él vino a causar grandes perjuicios y ningún beneficio para España ni para el indígena... Desde esta época empieza para un súbdito español residente en Santa Isabel, de Fernando Póo, D. Jesús Requena, un calvario que, desgraciadamente para él, aún no ha terminado. Antes de publicarse el decreto de referencia, a primeros de Septiembre, se pretendió aplicarlo arbitrariamente a D. Jesús Requena, para lo cual, al llegar su primer pedido de vino en los primeros dias se Septiembre e ir a recogerlo al puerto, se encontró con que en la Aduana había orden de la Policía de incautación por orden gubernativa. Tras largo calvario se consiguió que al fin el gobernador permitiera la retirada del vino, pero negándose a dar permiso de venta del mismo. Por carecer del permiso no pudo venderse el vino hasta que el gobernador, un mes más tarde, lo autorizó, después de haberle causado perjuicios irreparables por la pérdida de pedidos importantes que el Sr. Requena no pudo servir... Desde primeros de Enero del año en curso el establecimiento de D. Jesús Requena continuamente vigilado por la Policía, dándose el caso que los mismos vigilantes pretendian se les vendiera a ellos vino sin autorización, para hacerle faltar al reglamento. El día 30 de Enero, a las doce del día, media hora después de haber cerrado el Establecimiento y a unos 200 metros del mismo, la Policia pregunta a unos indigenas si habian bebido vino; éstos contestan que habian bebido una botella, y a las pocas horas, sin llamar al Sr. Requena a declarar, sin averiguar la verdad de lo ocurrido, el gobernador decreta la clausura del establecimiento y el decomiso de todas las importantes mercancias que en él habia, que pasan de 100.000 pesetas... Contra tan arbitraria resolución don Jesús Requena, sin que hasta la fecha se haya resuelto el recurso, existiendo el temor de que en la actualidad, como consecuencia del clima de los trópicos, la mercancía esté averiada y totalmente inservible... Como por las razones expuestas el excelentísimo Sr. Presidente del Consejo comprenderá que, dada la cuantía del comiso, el asunto sale de la esfera gubernativa para entrar en la politica, ya que hay motivos fundados para creer [que] se trata de una venganza política, es por lo que el Diputado que suscribe solicita del Excmo. Sr. Presidente del Consejo de Ministros reclame del Gobierno general de Golfo de Guinea los expedientes gubernativos que hagan referencia a D. Jesús Requena y los ponga a la disposición de la Cámara y del firmante para su estudio inmediato. Palacio de las Cortes, a 3 de abril de 1934 - Julio Moreno Dávila”. Véase Diario de Sesiones, sesión de 04/04/1934, pp. 520-521. También se hace referencia a lo anterior AGA 88 (81/6357), escrito de 10/04/1934 firmado por la presidencia del consejo de ministros, dirección general de Marruecos y Colonias.

78 "Que se digne disponer lo necesario para que por los servicios correspondientes de la Dirección de su digno cargo se remita, con la urgencia posible, a la Cámara el expediente relativo a las protestas que se han suscitado contra el decreto publicado por el gobernador general de los Territorios españoles del Golfo de Guinea en el "Boletín Oficial" de fecha de $1^{\circ}$ de Octubre de 1933, reglamentando la venta de bebidas alcohólicas en dichos territorios, así como las siguientes informaciones... $1^{\text {a }} \mathrm{Si}$, de conformidad con lo que dispone la ley de 26 de Mayo de 1933, antes de dictarse y aplicarse [el] decreto de referencia, se solicitó informe del Instituto Nacional del Vino y de la Dirección general de Comercio y Política Arancelaria... 2 $2^{\text {a }}$ Qué elementos informativos sirvieron de base al señor gobernador general para llegar a la conclusión de que se imponían las medidas contenidas en la citada disposición...,,, $3^{\mathrm{a}} \mathrm{Si}$ antes de la vigencia de este decreto se procedió a la aplicación de alguna de las medidas en él contenidas contra algún individuo español establecido en dichas Colonias... $4^{\mathrm{a}}$ Consumo, durante el último quinquenio, de vinos y bebidas alcohólicas en Fernando Póo... $5^{\mathrm{a}}$ Posibilidades que tiene la Colonia sobre el consumo de vinos y bebidas alcohólicas... $6^{\mathrm{a}}$ Efecto de carácter social, sanitario y económico que ha producido la aplicación del mencionado decreto, según los informes oficiales... $7^{\mathrm{a}}$ Restricción que se ha operado en el consumo del "tope" como consecuencia de las medidas adoptadas... 8 ${ }^{\text {a }}$ Ordenanzas adoptadas por el señor gobernador general para la aplicación de su decreto. [pie del escrito] Palacio del Congreso, 31 de Marzo de 1934.- Juan J. Palomino”. Véase Diario de sesiones, sesión de 10/04/1934. Cf. también AGA 88 (81/6357), escrito de 26/04/1934, firmado por la 
Requena, un colono al que el gobernador Lluesma había sancionado por incumplimiento de la normativa en materia venta de bebidas alcohólicas, la Inspección General de Colonias emitió una propuesta de resolución ${ }^{79}$ del recurso de alzada interpuesto por el sancionado ante la presidencia del gobierno ${ }^{80}$. En su resolución provisional, la Inspección no se limitó a afirmar la facultad sancionadora del gobernador sino que también, al desvirtuar la argumentación jurídica esgrimida por el recurrente, despejó una vez más cualquier duda que Requena y otros pudieran albergar sobre el verdadero significado de principios coloniales claves, como la potestad reglamentaria del presidente en materia colonial, la adaptación de la norma metropolitana a la realidad colonial, la facultad del gobernador para ejecutar los reglamentos del presidente y dictar ordenanzas provisionales y urgentes, y la interpretación especial de las garantías constitucionales en el espacio colonial. Antes de analizar el razonamiento de la Inspección, conviene recordar previamente los hechos alegados por el recurrente y la fundamentación jurídica de sus pretensiones.

Según el relato de Requena ${ }^{81}$, la secuencia de hechos que resultó en la imposición de las sanciones recurridas fue como sigue. Entre el 5 y 10 de octubre de 1933 este interesado acudió a la aduana para retirar un pedido de vinos que había llegado de la Península. Pero los agentes, siguiendo una orden del gobernador general del 5 del mismo mes, se negaron a consignar el pedido, alegando que Requena carecía de autorización para importar vino. Requena solicitó la exhibición de la disposición que prescribía la referida autorización, pero el gobernador respondió con evasivas, así que el colono no tuvo otra elección que solicitar la autorización. Una vez presentada la solicitud, el secretario general del gobierno colonial le comunicó que se le concedia el permiso con la condición de firmar un escrito de renuncia a su derecho a importar vino en el futuro. Ante la negativa de Requena se le concedió el permiso con fecha 9 de octubre de 1933. Pero como esta autorización sólo valía para retirar su pedido, no para venderlo, Requena solicitó de otro permiso, que le fue concedido el 31 de octubre de 1933. Pero para la concesión de esta última autorización se le exigió someterse anticipadamente al nuevo reglamento de venta de bebidas alcohólicas de 25 de septiembre de $1933^{82}$, cuyo art. 1 fijaba su entrada en vigor a partir del 31 de

presidencia del consejo de ministros, dirección general de Marruecos y Colonias - sección de colonias.

79 AGA 88 (81/6357), escrito de 29/09/1934 de la inspección general de colonias (sección administrativa y comercial) por el que se emite propuesta de resolución del recurso de alzada interpuesto por Jesús Requena.

$80 \mathrm{E} 1$ recurso de alzada de Requena fue admitido a trámite por la presidencia del consejo de ministros el 13 de agosto de 1934.

81 AGA, de la caja precedente, escrito de 11/09/1934, que reproduce los fundamentos fácticos alegados por Requena.

82 El contenido del reglamento puede resumir como sigue. Según el art.1 de este reglamento, a partir del 31 de diciembre del mismo año, quedaban extinguidas todas las autorizaciones concedidas hasta entonces para la venta de bebidas alcohólicas. Desde la misma fecha, seguía el art.2 de la norma, se empezaba a conceder nueva autorizaciones anuales (caducaban el 31 de cada año) tanto para bares como para otros comercios de venta de vino y alcoholes. En el caso de los bares, el decreto, además de prohibir el despacho de alcohol para su consumo fuera del establecimiento (art.2.I.a), vedó la venta tanto para indigenas no emancipados (naturales o extranjeros) como para sujetos en estado de embriaguez o predispuestos a ella (art.2.I. b y c). En el caso de los comercios de venta de vino y alcoholes, se prohibió su consumo 
diciembre de 1933. Siguiendo este mismo precepto el recurrente obtuvo la renovación de su permiso de venta el 27 de diciembre de 1933, cinco días después de haberla solicitado. Parece que el gobernador no se dio por vencido en sus frustrados intentos de sancionar a Requena, y ordenó que su establecimiento fuera siempre vigilado 'para sancionarlo a la mínima violación de la norma. Y, efectivamente, el 29 de enero de 1934 Requena recibió una multa de 500 pesetas por vender bebidas alcohólicas después de las $6 \mathrm{~h}$ de la tarde. Al día siguiente, a las doce de la mañana según el diputado Morano Dávila, se procedió a la clausura del local de Requena y se declaró el decomiso del género hallado en su interior. El sancionado consideró injusta la decisión y recurrió en alzada al presidente del consejo de ministros, quien admitió a trámite su recurso el 13 de agosto de 193483 .

Al leer el recurso de Requena se observa una estrategia defensiva que desvirtuaba la resolución del gobernador en tres líneas argumentales. Requena sostuvo, en primer lugar, la improcedencia de las sanciones alegando que el reglamento sobre el horario de locales comerciales fijaba el cierre a las $8 \mathrm{~h}$ de la tarde; sostuvo además el carácter antidemocrático tanto de la potestad reglamentaria del presidente en materia colonial, como de los ilimitados poderes sancionadores del gobernador; finalmente, denunció ser castigado con las sanciones máximas mientras otros infractores fueron sancionados con multas (entre 25 y 75 pesetas) o simplemente perdonados, como un Sr. Peraita. Si uno de estos argumentos debía considerarse improcedente era precisamente el primero, pues la disposición esgrimida por Requena el reglamento regulador del horario de cierre de locales comerciales 84 establecía que el despacho de bebidas alcohólicas después de las $5 \mathrm{~h}$ debía sancionarse con una multa de 500 pesetas la primera vez, de 1.000 pesetas en la primera reincidencia y con clausura del local a partir de la segunda reincidencia (art. 1, art. 4 y art. 5). Consecuentemente, si la decisión del gobernador resultaba infundada respecto de la clausura de local (pues se trataba de la primera infracción éste), no lo fue, sin embargo, la imposición de una multa de 500 pesetas.

En cuanto a su ataque al carácter antidemocrático de las potestades reglamentarias en materia colonial la fundamentación jurídica de Requena no desmereció algún mérito. El interesado entendió que los derechos y deberes de los españoles residentes en la colonia, "regulados por la Constitución de la

dentro del establecimiento (art.2.II.a), y se impuso la tenencia de una autorización de la Policía gubernativa para la expedición de alcohol a indigenas (naturales o extranjeros) emancipados o no emancipados (art.2.II.b y c). Como puede observarse, este art.2, además de desmentir la presumida igualdad jurídica entre blancos y nativos emancipados, venía a restar toda eficacia a la prohibición del precepto presente: pues los no emancipados, si no en los bares, podían perfectamente adquirir alcohol en los establecimientos de vino y alcoholes, sobre los que sólo se impuso, además de la referida autorización, la obligación de exhibir mensualmente un inventario tanto de las "existencias alcohólicas" como de las ventas realizadas. El art. 3 prohibió a la Aduana entregar productos alcohólicos a consignatarios carentes de las autorizaciones establecidas. La violación de las disposiciones del decreto se castigó generalmente con el decomiso de todos los "géneros alcohólicos"; y si el infractor carecía de autorización de venta de alcohol, se le podía expulsar también de la colonia. Véase Agustín Miranda Junco, Leyes coloniales..., op. cit., p. 870

83 AGA 88 (81/6357), expte. $n^{\circ} 75 / 9$, escrito de 11 de septiembre de 1934, sobre el recurso interpuesto por Jesús Requena ante la presidencia del consejo de ministros.

84 Agustín Miranda Junco, Leyes coloniales..., op. cit., p. 624; AGA G-1900 (81/8169), expte. $\mathrm{n}^{\mathrm{o}} 2$ 
República española" según la primera proposición de la base $7^{a}$ del ECR, debían de estar sujetos a una interpretación sistemático-constitucional. Así esgrimió el art. 44 de la Carta magna, cuyo párrafo segundo sostenía que los ciudadanos podian ser privados de su derecho de propiedad pero sólo mediante un procedimiento expropiatorio fundado en "causa de utilidad pública" y con una "adecuada indemnización"85. También alegó que la potestad legislativa, atribución exclusiva del pueblo, sólo podía ser ejercida por las Cortes, representantes del verdadero soberano a tenor del art. 5186. Partiendo de estas premisas, Requena sostuvo que la base $2^{\mathrm{a}}$ del ECR, aunque su tenor pareciese sugerir lo contrario, jamás significó atribuir al gobernador general facultades legislativas susceptibles de derogar disposiciones constitucionales. Antes al contrario: la potestad reglamentaria del gobernador, siendo una facultad delegada y provisional como establecía la base $14^{\mathrm{a}}$ del ECR, no sólo excluía la imposición de "penas de confiscación de bienes", también prohibida por el art. 44 de la constitución in fine; su ejercicio quedaba sujeto a la aprobación del poder central y a una necesaria ley previa cuyos límites de delegación no podian ser conculcados por el gobernador general. Basándose en estos argumentos Requena pidió el levantamiento de las sanciones y una indemnización por los daños y perjuicios económicos sufridos 87 .

Si el razonamiento de Requena tuvo un enfoque democrático-garantista, la argumentación de la Inspección de Colonias siguió una línea netamente colonialista, que partía solemnemente del carácter especial del ordenamiento jurídico colonial ${ }^{88}$. La colonia se concebía así desde la más absoluta ajenidad

85 Artículo 44 de la Constitución española del 31: "Toda la riqueza del país, sea quien fuere su dueño, está subordinada a los intereses de la economía nacional y afecta al sostenimiento de las cargas públicas, con arreglo a la Constitución y a las leyes. [Otro párrafo] La propiedad de toda clase de bienes podrá ser objeto de expropiación forzosa por causa de utilidad social mediante adecuada indemnización, a menos que disponga otra cosa una ley aprobada por los votos de la mayoría absoluta de las Cortes. [idem] Con los mismos requisitos la propiedad podrá ser socializada. [idem] Los servicios públicos y las explotaciones que afecten al interés común pueden ser nacionalizados en los casos en que la necesidad social así lo exija. [idem] El Estado podrá intervenir por ley la explotación y coordinación de industrias y empresas cuando así lo exigieran la racionalización de la producción y los intereses de la economía nacional. [idem] En ningún caso se impondrá la pena de confiscación de bienes".

86 Artículo 51 de la Constitución española del 31: "La potestad legislativa reside en el pueblo, que la ejerce por medio de las Cortes o Congreso de los Diputados".

87 "SUPLICO A .V.S. que teniendo por presentado este escrito con los documentos que se acompañan y con él por impugnadas las imputaciones que se me hacen en el expediente objeto de ese recurso, se sirva dictar resolución declarando haber lugar al de alzada que intereso y en su virtud, anular la resolución recurrida dictada por el Gobernador General de las Posesiones españolas del Golfo de Guinea en 30 de mayo de 1934, y acordar en consecuencia se levante y deje sin efecto el decomiso de los productos alcohólicos de mi propiedad que tenía almacenados y de los que se incautó el Gobernador dejándolos a mi disposición e indemnizándome de las pérdidas que haya sufrido, pues procede así en justicia que espero alcanzar de V.S. en Madrid a 11 de septiembre de 1934". Véase AGA 88 (81/6357), n 75/9, escrito de 11/09/1934 de recurso de alzada interpuesto por Jesús Requena ante el presidente del consejo de ministros.

88 "No existe colonia alguna en donde tengan efectividad todas las leyes metropolitanas con carácter general, porque el régimen de las Colonias exige una legislación especial y adecuada a las peculiaridades del país, siendo de advertir que aun en Colonias pertenecientes a una misma nación, es distinta la legislación por exigirlo así sus especiales características, en razón a lo variable de las razas, costumbres, condiciones geográficas y factores políticos que por su extraordinaria importancia precisan tener en cuenta... Y asi se comprende, por lo que se refiere a nuestra colonia que a las disposiciones de toda índole que diariamente aparecen en la Gaceta de 
respecto de la metrópoli. Entre ambas se extendia un vacío, una distancia cuya insuperabilidad dependia no sólo de factores físico-geográficos, sino también raciales, culturales, políticos, sociales, económicos. Desde la asunción de esta mutua exclusión, la Inspección rechazó cualquier tesis partidaria de concebir el territorio colonial como espacio jurídicamente asimilado. Para el órgano central, la norma metropolitana, producto de factores condicionantes de la realidad metropolitana, sólo podía ser aplicada en los territorios coloniales tras pasar por un proceso de adecuación a las circunstancias y particularidades locales. Pero dada la "copiosísima" normativa aprobada en la metrópoli, dada igualmente la "absoluta imposibilidad" que suponía adaptar diaria y constantemente esas disposiciones, lo lógico y razonable era concebir la geografia colonial como un espacio donde la aplicación íntegra de una disposición metropolitana no sólo podía realizarse en casos muy concretos, sino que además suponía una rara excepción al principio general en la materia: esto es, la no aplicación de la ley metropolitana en el territorio colonial o, lo que venía a ser lo mismo, la adaptación de esa ley a la supuesta realidad de la colonia. Sobre tal razonamiento, la Inspección juzgaba "errónea" cualquier interpretación sistemático-constitucional de los derechos reconocidos en la base $7^{\text {a }}$ del ECR; su principio rector -su verdadera ratio- radicaba, no en la proposición principal del primer párrafo ("los derechos y deberes de los españoles y extranjeros... serán regulados por la Constitución"), sino en la proposición subordinada que lo cerraba ("salvo las adaptaciones que a propuesta del Gobernador se acuerden por el Gobierno") ${ }^{89}$. Así pues, contra el entendimiento de Requena y de algún que otro colono, el alcance y el contenido de los derechos de los colonos se definían en los reglamentos del Ejecutivo central y del gobernador, y no en la legislación o en la jurisprudencia metropolitanas. La República, igual que la extinta monarquía, había dejado los derechos bajo control absoluto del poder colonial.

En cuanto a la crítica o denuncia contra el nuevo reglamento de venta de bebidas alcohólicas y la facultad sancionadora del gobernador, la Inspección empezó por advertir que la prohibición de vender alcohol a los indígenas no

\footnotetext{
Madrid, no pueda dárseles vigencia en aquellos, en atención a la absoluta imposibilidad de acompasar y adaptar diariamente en forma copiosísima y constante una legislación inadecuada (un ejemplo de ello es la copiosísima legislación social), por hallarse la colonia en una estado embrionario desde los puntos de vista social, cultural y de iniciación de los intereses materiales de los indígenas... Por ello, se presentan en el régimen y gobierno de las Posesiones de Guinea tres modalidades distintas en lo que se refieren a las materias que han de ser objeto de disposiciones adecuadas: primero, aplicación en la Colonia de la legislación metropolitana; segundo, adaptación de la misma a las conveniencias de régimen colonial; tercero, inaplicación absoluta de las disposiciones de la metrópoli... Ante estas consideraciones, resulta evidente que en momentos de urgencia que solo al Gobierno Central corresponde apreciar, puede ser preciso dictar disposiciones provisionales que no por tener este carácter han de carecer de efectividad a ponerse en vigor... Cuestión esta, la legislativa, de la mayor importancia en un régimen colonial en donde precisa efectuar un detenidísimo estudio sobre cualquier cuestión para el aprovechamiento, adaptación o exclusión de los preceptos establecidos en las disposiciones metropolitanas, y que en relación con las cuestiones que se plantean en este expediente, es de gran interés tener en cuenta".

89 "Por lo expuesto, estima el infrascrito [se refiere al Inspector General de Colonias] que en los repetidos titulados "Fundamentos de Derecho" se da a la base $7^{\text {a }}$ del Decreto de 22 de julio de 1931, respecto a los derechos y deberes de los españoles, una interpretación que no puede tener otro alcance que el determinado taxativamente en las últimas palabras de la misma, esto es, "salvo las adaptaciones que a propuesta del Gobernador se aprueben por el Gobierno".
} 
emancipados no era un caso aislado del colonialismo español; era el compromiso asumido por las potencias en virtud del tratado de Saint-Germain (10 de setiembre de 1919)90. Así que el nuevo reglamento colonial de 1933, igual que sus equivalentes en las colonias africanas de otros países europeos ${ }^{91}$, sólo introdujo una medida eficaz para cumplir la referida obligación internacional que, por cierto, tenía un claro trasfondo económico. Como se deduce de la exposición del reglamento y de las consideraciones de la Inspección ${ }^{92}$, en una economía marcada, como la guineana, por la carencia de mano de obra, un descontrol en la de venta de bebidas espirituosas sólo empeoraba el estado de las cosas. Pues el "progresivo aniquilamiento" de los indígenas por su afición al alcohol, además frustrar los objetivos "de velar por la salud y el bienestar general de los nativos", reducía más y más la poca mano de obra local y dificultaba la contratación de súbditos coloniales extranjeros, cuyos gobiernos eran cada vez más exigentes con la prohibición de venta de alcohol a sus pupilos. Urgía, pues, la adopción de medidas por el Ejecutivo central; como legislador exclusivo en materia colonial (art.14 de la Constitución del 31 y art. 14 del ECR), éste podía elegir entre aprobar un reglamento con sanciones contra las ventas prohibidas o, si así lo juzgaba conveniente para el "mejor gobierno" de Guinea, delegar el ejercicio de esa potestad en la Inspección General de Colonias o en el gobernador de los TTEEGG93. La Inspección, pese a rechazar la fundamentación jurídica alegada por el recurrente, terminó por proponer a la minoración de la responsabilidad exigida a Requena ${ }^{94}$.

Según quedó reafirmado en este caso, la facultad sancionadora del gobernador, ya fuese ejercida por la vía de las "ordenanzas provisionales y urgentes" de la base $14^{\mathrm{a}}$ del ECR, ya mediante la ejecución ordinaria de disposiciones emanadas del Ejecutivo central por delegación del presidente de la

90 En realidad, este tratado remitía a su vez al art. 22 del tratado de Versalles, que establecía la prohibición de vender bebidas alcohólicas a nativos de los territorios bajo mandato.

91 Se citaban los ejemplos de Tanganika, Togo, Eritrea, Somalia o Madagascar. Véase AGA 88 (81/6357), expte. $n^{\circ} 75 / 9$, propuesta de resolución del recurso de alzada por la Inspección General de Colonias, sección Administrativa y Comercial, 29/09/1934.

92 "Además de ser manifiesta la decadencia de la raza indígena como consecuencia del abuso a que les lleva su afición al alcohol y que determina su progresivo aniquilamiento, necesita nuestra Colonia para su explotación disponer de un número suficiente de braceros indígenas, lo cual constituye uno de los problemas de mayor gravedad que precisa resolver en aquellos territorios, habiendo constituido hasta el día la falta de un reglamento de bebidas alcohólicas (en confirmación de medidas adoptadas en todas épocas) un obstáculo para encontrar soluciones adecuadas que permiten celebrar convenios con las demás Colonias africanas y que sea garantía de la seguridad que aquellas autoridades imponen respecto a la protección del indigena". De la misma caja, expte. $n^{\circ} 75 / 9$, escrito de la presidencia del consejo de ministros, Dirección General de Marruecos y Colonias, sección de colonias, 06/03/1934.

93 "Siendo de la competencia del Gobierno Central la función adaptadora de las leyes, y estando a su cargo el régimen colonial, es facultad del Gobierno, en los casos de urgencia, la reglamentaria, aun sin la previa adaptación, como asimismo delegar ésta en el Gobernador general cuando así convenga al mejor gobierno de aquellos territorios”. Véase AGA 88 (81/6357), expte. $n^{\circ} 75 / 9$, propuesta de resolución del recurso de alzada de Requena (06/03/1934).

94 "Como resumen de cuanto se expone en lo que antecede, el funcionario que tiene el honor de informar a V. E. es de parecer que debe considerarse establecida en el citado artículo $4^{\circ}$ de Reglamento una imposición de sanciones progresiva en tres grados, y considerar incurso al señor Requena en la responsabilidad menor. V.E., no obstante, resolverá". AGA, caja y expediente precedentes. 
República, era absoluta si una delegación expresa no había establecido los limites. No obstante este carácter su ejercicio, al menos formalmente, estaba sujeto a unos principios complementarios que, sin mermar el poder del gobernador, introducian algún que otro matiz en su alcance. Podemos recordar, en tal sentido, el carácter potestativo de la intervención del gobernador general para castigar faltas leves de los funcionarios, su competencia exclusiva en la sanción de las faltas graves y muy graves de éstos, la exigencia de tramitación de expediente para la separación definitiva del servicio y, en fin, el recurso de alzada contra las sanciones graves y muy graves. Todos estos principios se contenian en el Estatuto de los funcionarios coloniales, de 8 de diciembre de 1931.

Según su art. 20. $1^{\text {a }}$ eran los jefes inmediatos la autoridad competente para amonestar o aplicar la "reprensión privada" a los subordinados incursos en una conducta definida como falta leve en el art.19. $1^{\circ}$ del Estatuto: "el retraso en el desempeño de las funciones que le estén encomendadas, sin sensible perturbación para el servicio; la negligencia o descuido excusables y la falta no reiterada de asistencia al servicio sin causa justificada"95. Por su parte, el gobernador, para castigar las faltas graves ${ }^{96}$, podia elegir entre las tres siguientes correcciones: "represión pública; multa de uno a quince días de haber; suspensión de empleo y sueldo de un mes a un año" (art. 20. 2 $2^{\mathrm{a}}, 3^{\mathrm{a}}$ y $4^{\mathrm{a}}$ ). La "separación definitiva del servicio" (art. 20. 5 ${ }^{\mathrm{a}}$ ), máxima corrección que podia imponer el gobernador, se reservó para conductas tales como "el abandono del servicio, las [faltas] contrarias al secreto profesional, la insubordinación en forma de amenaza individual o colectiva, la emisión a sabiendas por negligencia o ignorancias inexcusables de informes oficiales, manifiestamente falsos, o la adopción de acuerdos manifiestamente injustos, las faltas de probidad y las constitutivas de delitos" (art. 19. 3ª).

La reprensión privada se aplicaba por escrito y debía constar en el expediente $u$ hoja de servicio del funcionario. La reincidencia en la comisión de falta leve motivaba la intervención del gobernador mediante la aplicación de la reprensión pública. Por su parte, a la tercera represión pública, o a la tercera multa aplicada a un funcionario, el responsable de las faltas se sometía a un expediente de cese o separación definitiva. Según el art. 20 las correcciones administrativas eran perfectamente compatibles con las sanciones de otra naturaleza derivadas de la calificación de los hechos ante otros órdenes jurisdiccionales. En otras palabras, el funcionario, por unos mismos hechos, podía estar sujeto a un procedimiento administrativo y un proceso judicial. En cualquiera de los casos, pendiente el primero el gobernador suspendía al funcionario de empleo y sueldo. Pero, si asi lo aconsejaban las circunstancias y las cargas familiares del expedientado, podía acordar una suspensión de sólo la mitad del sueldo mientras se tramitase el expediente. Una vez finalizado, si no quedó probada la irregularidad el funcionario era repuesto y se le debía reintegrar el sueldo que había dejado de percibir. Si, por el contrario, resultaba probada su falta, el funcionario era separado definitivamente, sin posibilidad de trabajar

95 Agustin Miranda Junco, Leyes coloniales..., op. cit., p. 823

96 Art.19.2 ${ }^{\circ}$ del Estatuto de funcionarios: "La indisciplina contra los superiores, la desconsideración a éstos o a público en actos de servicio, los altercados o pendencias dentro de las oficinas, aunque no constituyan delito ni falta punible; las informalidades o el retraso en el despacho de los asuntos, cuando perturbe sensiblemente el servicio, y la de negarse a prestar servicio extraordinario en los casos en que lo ordenen por escrito los superiores". 
nuevamente en la Administración colonial. En este último caso el separado, en el plazo de dos meses desde la recepción de la resolución definitiva, podía interponer recurso de alzada ante la presidencia del consejo de ministros o ante la dirección general de Marruecos y Colonias.

Aunque el estatuto de los funcionarios era aplicable a toda la Administración colonial, algunas normas sectoriales quisieron aligerar el trabajo del gobernador general, librándolo de sancionar todas las faltas leves cometidas por los empleados a sus órdenes. Por ejemplo, el art. 9 del Reglamento del Hospital General de Santa Isabel estableció que director del establecimiento, además de estar obligado a informar a la superioridad de las faltas cometidas por el personal del hospital, podia castigar las del personal indigena, con multas cuyas cuantias debían ser proporcionales a la entidad de las faltas sancionadas ${ }^{97}$. Lo mismo cabe decir de las ordenanzas provisionales de la dirección de Sanidad (6 de julio de 1934), cuyo art. 9 permitía al jefe del Servicio sanitario no sólo proponer al gobernador las sanciones aplicables a faltas contra las ordenanzas, sino también imponer sanciones (que no podian exceder de un día de haber para empleados europeos).

Otro bloque normativo que introdujo matices importantes respecto de la potestad sancionadora del gobernador se relacionó con la regulación del "trabajo indigena". Desde el primer reglamento sobre la cuestión (1906) funcionó una jurisdicción especial a cargo de la Curaduría colonial, encargada de resolver los litigios surgidos de los contratos laborales entre europeos e indígenas (art. 4) y de aplicar las sanciones establecidas por la ley en la materia ${ }^{98}$. El sistema punitivo del reglamento era bastante simple. En relación con los incumplimientos del trabajador, el art. 71 estableció con ambigüedad que el curador debía castigarlos "prudencialmente". Respecto de la fuga del bracero, única falta individualizada por el legislador de 1906, se estableció una pena de diez días de cárcel para la primera comisión (art. 72) y trabajos forzosos en obras públicas por la mitad del salario a partir de la primera reincidencia, siempre que el antiguo patrono se negase a emplearlo (art. 74). Por su parte, respecto de los patronos, la norma incidió en dos incumplimientos. Así, el art. 73 impuso una multa de 500 pesetas al propietario que no hubiese comunicado a la Curaduría la fuga de un trabajador de otra finca refugiado en la propia. Por otro lado, se estableció una multa de 100 pesetas para todo propietario que aplicara violencia o castigos corporales al trabajador (art. 69). Además, el art. 75 . $6^{\circ}$ autorizó la resolución del contrato para el caso de que dichos actos violentos hubiesen resultado en incapacidad laboral permanente o transitoria del bracero, y que el patrono fuera condenado por sentencia firme. Una regla inhumana y esclavista, pues el bracero no podía librarse del contrato aun cuando sufriera sistemáticamente maltratos que, aunque sancionados por el curador, sin causar incapacidad bien podian originar otras lesiones. La exigencia de sentencia firme tampoco ayudaba mucho a la liberación del bracero. Lógicamente, entre las

97 Art.9 del Reglamento del Hospital Genera de Santa Isabel: "Tendrá el deber de dar cuenta a la superioridad de las faltas cometidas por el personal europeo e indigena en el cumplimiento de sus funciones, para que la superioridad proponga las sanciones que crea oportunas. Respecto del personal indigena estará facultado para imponer multas cuya cuantía dependerá de la falta cometida, dando cuenta de las sanciones impuestas y su causa a la jefatura de servicio". Véase AGA G-1830 (81/8099), expte. nº 23.

98 Agustín Miranda Junco, Leyes coloniales..., op. cit., pp. 205-212 
pruebas más relevantes para condenar al maltratador estaban los testimonios de los compañeros del trabajador maltratado. Pero, ¿cómo iban a declarar contra un patrono capaz de tomar represalias?

El reglamento del trabajo indígena de 1913 introdujo reformas importantes en el régimen de sanciones apenas descrito ${ }^{99}$. Según su art. $3^{\circ}$, párrafo $5^{\circ}$, el curador, tras constatar la veracidad de una reclamación presentada por el bracero por impago del total o parte de su haber, imponía al patrono una multa de 50 pesetas, cantidad elevada al doble en caso de primera reincidencia y al cuádruple en las sucesivas. Si esta situación de impago de haberes se registraba durante tres meses, el art. 2, párrafo $7^{\circ}$, la anulación de los contratos entre los braceros afectados y el patrono; éste perdía los braceros y el curador "procederá a entablar la demanda correspondiente ante el Juzgado". Junto a las reglas para el impago el decreto de 1913 modificó también el régimen de sanciones por malos tratos. En virtud del art. 4 la multa inicial de 100 pesetas subia a 150 en la primera reincidencia y a 250 en la segunda. A partir de la tercera reincidencia, esto es, la cuarta vez que se dieran maltratos, se presentaban dos supuestos, según el infractor fuera el propietario mismo o un dependiente; en este supuesto el finquero tenía la opción de despedir al infractor o padecer la retirada de los braceros. Pero si el propietario era el infractor sufría la multa de 250 pesetas y una seria amonestación, retirándosele los braceros de persistir en su violenta conducta. Para la aplicación de las correcciones por malos tratos, el curador debía de abrir una información (esto es, tramitar un expediente con audiencia al interesado, a la víctima y a los demás testigos) cuya resolución final tenía en cuenta las atenuantes y las agravantes concurrentes. Por ejemplo, si resultaba que el maltrato tuvo origen en una falta del trabajador y consistió sólo en un bofetón o un golpe sin mayores consecuencias, el curador, además de aplicar la citada escala de multas, castigaba al bracero con cinco días de cárcel y una disminución de haber por los dias de encierro. Pero si resultaba de la información que hubo ensañamiento por parte del patrono y el maltrato era causa de lesiones, entonces el curador, además de retirar los braceros y obligarle a cubrir los cuidados que necesitare el ofendido, emprendía acciones legales contra el finquero, incluida la pertinente indemnización.

Las faltas de los braceros se castigaban con pena de prisión. Por "negarse a trabajar sin causa justificada" se imponia una retención de 5 a 20 días (art. 5. a); por "ausentarse de la finca sin permiso" o por "desobediencia contumaz", el castigo era de 5 a 30 dias (art.5. b y c); en caso de "insubordinación acompañada de agresión a las personas o la propiedad" la privación de libertad subía de 30 a 60 dias (art. 5. d); por presentar "quejas injustificadas cuya falsedad se compruebe", una detención de 15 a 30 dias; finalmente, la "incitación a otros braceros a abandonar el trabajo, ya sea en su finca, ya sea en otras" acarreaba prisión de 5 a 90 dias. Lógicamente, durante los días en que el bracero permaneciera "detenido en el barracón" era empleado en obras públicas sin remuneración alguna, y perdia los haberes pactados con el patrono; tampoco los días de detención valían a los efectos de la duración del contrato. Si la agresión perpetrada por el bracero hubiera resultado en lesiones o daños sobre la propiedad se le ponía a disposición de la autoridad judicial.

Tanto los patronos como los trabajadores podían recurrir las resoluciones

99 Ibidem, pp. 392-397 
del curador ante el gobernador general; los primeros en plazo de cinco días para interponer la alzada a contar desde la notificación de la resolución. Para los segundos el plazo se extendía tres días más.

Hasta la caída de la República en Guinea (14 de octubre de 1936) las principales reformas que experimentó el régimen sancionador descrito solamente afectaron la graduación de las multas por malos tratos. Así, una real orden de 15 de junio de 1929 estableció para la primera infracción multa de 100 a 250 pesetas, que subian a multa de 250 a 500 pesetas para los reincidentes; sucesivas faltas eran castigadas con pena de 500 a 1000 pesetas $^{100}$. El reglamento laboral de 1935 mantuvo esta escala hasta que el 28 de junio de 1936 una nueva ordenanza del gobernador elevó considerablemente las multas por maltrato. El art. $1^{\circ}$ de la misma castigaba esas faltas con multa de 1000 a 2500 pesetas; la reincidencia merecía una multa de 2500 a 10.000 pesetas. El art. $2^{\circ}$ introducía la responsabilidad subsidiaria de los patronos por infracciones de sus dependientes. Y el art. $3^{\circ}$ dejaba claro que las referidas multas eran aplicables sin perjuicio de la represión penal que merecieran los hechos así castigados.

Como se concluye de lo anterior, no fue menor el poder sancionador que correspondía al curador colonial en la materia del trabajo indígena. Al defensor de los derechos de los súbditos no emancipados quedaba la decisión de imponer multas de insignificante cuantía hasta sanciones más serias, como la "prohibición de contratar con indígenas" o "la expulsión de la colonia", decisiones que comprometían el ejercicio de libertades legales. Pero tal jurisdicción especial nunca mermó el poder del gobernador general, libre de reprimir cualquier incumplimiento laboral que llegara a su noticia, personalmente o por denuncia de colonos y colonizados. Su autoridad se dejaba notar aún más a la hora de ejecutar las sanciones impuestas por el curador, quien, pese a ser el oficial competente, actuaba como mero "decisor provisional". En otras palabras, el curador no tenía la misma libertad para castigar las faltas leves de los patronos coma para imponerles sanciones más graves. Mientras podía informar a posteriori al gobernador de las multas que les hubiera impuesto, en el caso de sanciones como la retirada de braceros o la expulsión de la colonia debía comunicarlo a priori. Es decir, el curador formulaba su propuesta en las conclusiones del expediente que elevaba al gobernador para resolución definitiva. Conocemos, por ejemplo, las informaciones o expedientes tramitados para retirar la autorización de reclutar braceros a un Arnol Wutow ${ }^{101}$ o a la compañía Druman S.A ${ }^{102}$, así como el expediente de expulsión de un Paulino Aramburuzabala103.

100 Ibidem, pp. 729-730

101 AGA G-1856 (81/8125), legajo I/expte. $n^{\circ} 23$, oficio de 25/09/1931 por el que se impone una multa de 500 pesetas al europeo Arnol Wutow y se propone le sea retirada la autorización para contratar braceros por el secuestro de mujeres nativas.

102 De la misma caja, resolución de 10/06/1935 por la que se retira a la Compañía Druman la autorización para contratar con indigenas.

103 Paulino Aramburuzabala, capataz de la finca de Santa María de la Casa Caifer, puso a trabajar al bracero Etogo Mbá estando enfermo. Según el bracero, el capataz le propinó un puñetazo en el costado. El bracero ingresó en el hospital de Santa Isabel, con síntomas de dificultad bronco-pulmonar posiblemente causados por el golpe. El curador, tras abrir expediente, impuso al capataz una multa de 250 pesetas y propuso que fuera expulsado. E1 juez de primera 
Después de lo expresado se puede concluir con la mención de una última facultad que también manifestaba el poder sancionador del gobernador. Aunque la Inspección de Colonias no se pronunció sobre esta cuestión en el caso Requena, la práctica reveló que el gobernador, pese a ejercer tal potestad como delegado del presidente de la República, podía a su vez delegar en los cargos coloniales que desempeñaban la representación del gobierno de la colonia (esto es, secretario general, subgobernador de Bata, y administradores territoriales), así como en cualquier otro alto funcionario. A diferencia de la delegación que recibía el gobernador, que era absoluta, la sub-delegación se reducía a la imposición de los correctivos de menor entidad.

\section{COMPETENCIAS DIPLOMÁTICAS DEL GOBERNADOR}

Como bien recuerda Drincourt Álvarez ${ }^{104}$, la expresión Estado colonial, o si se prefiere en plural, Estados coloniales, jamás debe confundirse con los territorios coloniales. Éstos, a diferencia de los protectorados, constituidos sobre el principio de soberania asistida 105 , eran considerados "partes integrantes" de las potencias colonizadoras, los verdaderos Estados coloniales. Cualquier negociación o relación establecida entre dos o más autoridades coloniales se entendía realizada en representación de los respectivos gobiernos metropolitanos. La base $2^{a}$ del ECR permitía que el gobernador, en materia de su competencia, pudiera establecer contacto con las autoridades de las colonias vecinas. Gracias a esta disposición los gobernadores republicanos, según habían hecho los monárquicos, negociaron con las colonias vecinas acuerdos y tratados luego ratificados por los ejecutivos metropolitanos. Por ejemplo, en 1931 una delegación oficial se desplazó de Fernando Póo a São Tomé e Príncipe al objeto de estudiar in situ la contratación braceros en aquella colonia portuguesa ${ }^{106}$. En

instancia e instrucción de Santa Isabel ordenó una investigación de los hechos pero terminó absolviendo a Aramburuzabala por incomparecencia de testigos. Fundado en su absolución Aramburuzabala recurrió la resolución del curador ante el gobernador, que estimó su recurso. Sobre estos particulares véase AGA G-1856 (81/8125), expediente sobre la muerte de Etogo Mba con el atestado del Hospital de Santa Isabel (23/10/1933); resolución de 24/10/1933 por la que el juez de Santa Isabel ordenaba la investigación de la muerte; oficio del curador $\mathrm{n}^{\circ} 240$ de 28/10/1933, con imposición de multa de 250 pesetas por la muerte de Etogo Mbá y propuesta de expulsión; sentencia del juicio de faltas (21/11/1934) con absolución de Aramburuzabala; recurso de alzada (23/11/1934) contra la multa de 250 pesetas; resolución del gobernador general (14/12/1934) estimatoria del recurso.

104 Juan Rodríguez- Drincourt-Álvarez, Estado constitucional: un análisis histórico de Francia (1871-1931) con referencia comparada a Gran Bretaña, op. cit., p. 43

105 Juan Rodríguez- Drincourt-Álvarez, Estado constitucional: un análisis histórico de Francia (1871-1931) con referencia comparada a Gran Bretaña, op. cit., p. 45-47; Martine Fabre, "L'indigénat: des petites polices discriminatoires et dérogatoires", Histoire du droit des colonies, 2010, p. 275, disponible en www.histoiredroitcolonies.fr ; Javier Alvarado Planas y Juan Carlos Domínguez Nafría, La Administración del Protectorado Español en Marruecos, op. cit., pp. 120-125; Santi Romano, Corso di diritto coloniale impartito nel R. Istituto di scienze social C. Alfieri di Firenze, op. cit., p. 35-48; acta general de la conferencia internacional de Algeciras (7 de abril de 1907), consultada en

lahistoriatrascendida.es/documentos/textos_juridicos/Acta_genera_conferencia_internacional_ algeciras_1906.pdf

106 AGA 146 (81/6415), expte. $n^{\circ} 133 / 20$, escrito de 16/05/1931 del gobernador a director general del protectorado y colonias. 
1933 el gobernador general puso a Antonio Nombela al frente de una comisión oficial que debía partir a Yaundé para negociar con esta colonia un tratado de cesión de braceros ${ }^{107}$; las negociaciones tuvieron como resultado un tratado firmado entre el gobierno español y el francés, de 8 de enero de 1934108 .

\section{OTRAS COMPETENCIAS.}

Como dirigente de la administración colonial, además de las analizadas se le reconocía al gobernador facultades inspectoras y presupuestarias. Como máximo supervisor del funcionamiento de la colonia, podía (debía hacerlo al menos una vez al mes) reunir a todos los jefes de servicios públicos para oír sus informes (base $5^{\mathrm{a}}$ ). Si asi lo exigían las necesidades locales insinuadas en los informes o en visitas de inspección, podía proponer la creación o constitución de los organismos públicos necesarios (base $8^{\mathrm{a}}$ ). En materia de presupuestos según el ECR “formulará el proyecto de Presupuesto anual de ingresos y gastos de la colonia y propondrá la alteración de los créditos del mismo; ordenará los gastos y dispondrá los pagos sujetándose al presupuesto y al resto de normativa" (base $\left.2^{\mathrm{a}}\right)$. Su aprobación era también necesaria para que fuese ejecutivo un acuerdo adoptado por un consejo de vecinos sobre los presupuestos municipales (base $8^{\mathrm{a})}$.

\section{CONSIDERACIONES FINALES.}

El advenimiento de la República fue aclamado en los TTEEGG. Lógicamente, en un espacio jurídico especial como lo había ido siempre Guinea, un himno de libertad e igualdad como el que supuso la declaración misma de la República, y un credo de justicia social como el que encarnó el discurso republicano, no pudieron sino ilusionar e infundir esperanzas en aquellos súbditos que, como bien recordó el diputado Alba en una sesión de las Constituyentes republicanas ${ }^{109}$, no habían conocido más que un régimen colonial militarizado que los mantuvo siempre al margen del hilo evolutivo de los derechos en la metrópoli.

Pero, no traicionar aquella esperanza de los coloniales en el nuevo régimen o, lo que es lo mismo, satisfacer sus expectativas hacia la nueva democracia española, era una cuestión que sumía a los republicanos en un aprieto ideológico, cuya solución pasaba, inevitablemente, por el sacrificio bien de los mismos valores republicanos bien de los principios "ontológicos" del colonialismo. Por un lado, eludir de plano las demandas de los residentes

107 AGA G-1856 (81/8125), memoria de los trabajos llevados a efecto por la comisión designada por el gobernador para negociar la salida de braceros de Camerún hacia Fernando Póo.

108 AGA G-1878 (81/8147), convenio de contratación de braceros cameruneses firmado en Yaundé el 8 de enero de 1934.

109 "Hasta hoy no se han aplicado en Guinea las leyes españolas más elementales relativas a la libertad individual; alli se ha estado siempre sometido a un régimen militar y de colonización que ha alcanzado no sólo a los indigenas, sino a los españoles que en Guinea residen. Por eso queremos nosotros que en la Constitución se haga constar que estos derechos individuales que otorgamos a todos los españoles se respetarán también en esos territorios. Nada más”. Véase Diario de sesiones, intervención de Guerra del Río en la sesión de las Constituyentes de $01 / 12 / 1931$. 
coloniales habria corroborado la preferencia de la República por la intangibilidad del ius commune colonial y habria supuesto identificar la República con un continuismo en el espacio colonial. Por otro lado, implantar aquella justicia formal y material que exigian los coloniales, aun siendo un deber impuesto por la coherencia del credo republicano, era una decisión que habría terminado con cuatro siglos de construcción de una filosofia de dominación. Asimilar constitucionalmente los TTEEGG, equiparar en derechos a metropolitanos y coloniales, y declarar la igualdad absoluta entre blancos y negros en Guinea, eran decisiones que destruían aquella línea roja que permitía distinguir claramente entre colonizadores o portadores de civilización y colonizados o asimiladores de los "superiores" valores culturales occidentales.

Ante tal complicado dilema, los republicanos no pudieron evitar incurrir en el mismo eclecticismo adoptado por la extinta monarquía en la Carta colonial de 1904. Tras declarar su intención de republicanizar y liberalizar el régimen colonial, y tras reconocer derechos constitucionales a los español y extranjeros residentes en Guinea, establecieron las facultades del gobernador tanto para adaptar las garantías constitucionales a las particularidades del espacio colonial como para adoptar cuantas medidas considerase necesarias para mantener la paz y la tranquilidad en los territorios bajo su jurisdicción.

Por si no bastaba el absolutismo del gobernador para desvirtuar aquellas tibias garantias establecidas a favor de los coloniales, ahí estaba el aparato administrativo para completar la tarea. Entre las causas que restaron eficacia tanto a la República de Weimar como a la española, los estudiosos suelen apuntar el hecho de que tales regimenes mantuvieron sendos aparatos judiciales cuyos miembros, en tanto reacios a los postulados republicanos, boicotearon, sistemáticamente, el funcionamiento de la administración judicial, desempeñando sus funciones jurisdiccionales de la manera que peor podía bloquear y frustrar los fines y propósitos republicanos. En el caso de los TTEEGG, la susodicha tesis debe aplicarse a todo el aparato administrativo colonial. El celo por mostrar siempre ante los colonizados una imagen de unidad entre los blancos hizo que los republicanos obviaran una limpieza ideológica en el seno de la administración colonial y mantuvieron casi intacto todo el equipo funcionarial del régimen precedente. La República confió así la praxis del derecho colonial a los mismos sujetos que no sólo eran los responsables de las arbitrariedades que caracterizaron la realidad de la colonia, sino que nunca tuvieron tiempo para instruirse y hacerse con los valores democráticos que debian regir entonces sus relaciones con los coloniales, sean éstos europeos o autóctonos.

Fecha de envio / Submission date: 9/12/2020

Fecha de aceptación / Acceptance date: 15/02/2021 